\title{
Helping You Help Me: The Role of Diagnostic (In)congruence in the Helping Process within Organizations
}

\section{Citation}

Fisher, Colin M., Julianna Pillemer, and Teresa M. Amabile. "Helping You Help Me: The Role of Diagnostic (In)congruence in the Helping Process within Organizations." Harvard Business School Working Paper, No. 14-003, July 2013.

\section{Permanent link}

http://nrs.harvard.edu/urn-3:HUL.InstRepos:11508209

\section{Terms of Use}

This article was downloaded from Harvard University's DASH repository, and is made available under the terms and conditions applicable to Open Access Policy Articles, as set forth at http:// nrs.harvard.edu/urn-3:HUL.InstRepos:dash.current.terms-of-use\#OAP

\section{Share Your Story}

The Harvard community has made this article openly available. Please share how this access benefits you. Submit a story. 
H A R VAR D

\section{Helping You Help Me: The Role of Diagnostic (In)congruence in the Helping Process within Organizations}

Colin M. Fisher

Julianna Pillemer

Teresa M. Amabile

\section{Working Paper}

14-003

July 2, 2013 


\title{
Helping You Help Me:
}

\section{The Role of Diagnostic (In)congruence in the Helping Process within Organizations}

\author{
Colin M. Fisher, Boston University \\ Julianna Pillemer, University of Pennsylvania \\ Teresa M. Amabile, Harvard University
}

\begin{abstract}
Through an inductive, multi-method field study at a major design firm, we investigated the helping process in project work and how that process affects the success of a helping episode, as perceived by help-givers and/or -receivers. We used daily diary entries and weekly interviews from four project teams, and a separate sample of critical incident interviews, to induce process models of successful and unsuccessful helping episodes. We found that, in unsuccessful episodes, help-givers and -receivers maintained incongruent expectations and project understandings throughout the episode, which we call diagnostic incongruence. In contrast, the parties in successful episodes engaged in aligning practices that fostered shared expectations and project understandings (i.e., diagnostic congruence). Importantly, aligning practices in successful episodes occurred before or at the beginning of episodes. We also found that people's assessments of unsuccessful episodes were often marked by intense emotionality, which sometimes led them to disregard whether the helping resulted in instrumental progress. We discuss the implications of our process model for theory and practice.

Keywords: Helping, Prosocial Behavior, Labor Process, Knowledge Management, Qualitative Methods, Field Study
\end{abstract}


Knowledge work in modern organizations is seldom an individual endeavor; coming up with new ideas and solving difficult problems is increasingly accomplished through collaboration and teamwork (Cohen and Bailey, 1997; Wuchty, Jones, and Uzzi, 2007). However, even when people collaborate to tackle a knowledge-intensive project, they often still need external help to achieve their goals (e.g., Ancona and Caldwell, 1992; Bresman, 2010). Scholars have used the term "helping" to describe a variety of discretionary interpersonal processes by which one party (the giver) allocates time and attention to a second party (the receiver) with the intent to benefit the second party (Bamberger, 2009; Grant and Patil, 2012). Forms of helping include assistance with task completion (e.g., Anderson and Williams, 1996), advice (e.g., Borgatti and Cross, 2003), team coaching (e.g., Hackman and Wageman, 2005), mentoring (e.g., Higgins and Kram, 2001), and socio-emotional support (e.g., Kahn, 1993).

Helping can be a crucial driver of collaboration in organizations (Katz and Kahn, 1966). Studies show that helping is associated with better organizational performance (e.g., Podsakoff et al., 2009), team effectiveness (e.g., MacKenzie, Podsakoff and Ahearne, 1998), and collective creativity (e.g., Hargadon and Bechky, 2006; Mueller and Kamdar, 2011). Further, many scholars have conceptualized helping as a fundamental building block of cooperation and teamwork in organizations (Weick, 1979; Flynn, 2006; Schein 2009; Grant and Patil, 2012) and have extolled the virtues of organizations that promote it (Ancona, Bresman, and Caldwell, 2009; Hansen, 2009; Amabile and Kramer, 2011). However, despite its potential benefits, helping can also be costly to the individuals involved in terms of time, effort, and/or reputation (Nadler, 1997; Flynn, 2006; Bergeron, 2007; Perlow, 1997).

Previous research has focused either on the positive organizational consequences of helping or on the antecedents of helping — the implicit cost/benefit analysis that organizational members 
perform as they decide whether to seek or give help. What happens between the antecedents and the consequences remains largely a black hole; surprisingly little is known about the helping process itself (Flynn, 2006; Bamberger, 2009). This is the gap that we seek to fill with the research presented here, believing, as Langley and colleagues (2013: 4) suggest, that understanding organizational processes is at least as important as understanding their antecedents and consequences. Moreover, although most prior research rests on the implicit assumption that organizational helping is always helpful, we take the contrary view that helping attempts can be useless or worse.

With these aims, we conducted an inductive field study of helping in a major design firm. In the spirit of Flynn's (2006: 165) call for researchers to examine helping behavior "at the episodic level,” we investigated discrete instances of helping. We qualitatively analyzed how the helping process unfolded, with a particular focus on aspects of the process, differentiating episodes that employees assessed as successful from those they deemed unsuccessful.

We define a helping episode as the interaction between a giver and a receiver around a bounded set of the receiver's issues. Because helping is often considered to be a discretionary, extra-role behavior (Organ, 1988; Van Dyne and LePine, 1998; Bergeron, 2007), helping episodes stretch or go beyond typical work duties; both parties must consent to engage in a helping episode, and both determine the terms of the interaction, either explicitly or implicitly. Further, because helping is discretionary, organizational members must perceive it positively in order to repeatedly engage in it (Grant and Patil, 2012). Thus, interactants’ subjective perceptions of helping's helpfulness can affect their willingness to seek or give help in the future (Flynn, 2006) and the degree to which productive norms for helping develop in an organization (Ehrhardt and Naumann, 2004; Grant and Patil, 2012). An important implication is that, to the 
extent that individuals perceive their prior experience with any particular helping episode to have been more or less successful, they will be more or less likely to engage in the discretionary behaviors of either seeking or giving help in the future.

\section{Prior Research: Whether Helping Happens}

The bulk of the literature on helping in organizations illuminates factors that determine whether helping happens — whether potential help-seekers or -givers will engage in those discretionary behaviors. Typically, studies examine the various costs and benefits that predict a help-seeker's success in getting a colleague to engage in helping behavior or, from the other perspective, the costs and benefits that predict a potential help-giver's willingness to engage in that behavior. As a result, existing theories focus on how help-seekers or potential help-givers carry out cost-benefit analyses that determine whether helping happens (Anderson and Williams, 1996; Bamberger, 2009).

Potential benefits to a help-seeker can include both instrumental and socio-emotional assistance. Instrumental help in organizations fosters the completion of a specific task or job requirement (Bamberger, 2009). Socio-emotional help (i.e., social support) is intended to improve the affective or physical well-being of the receiver, and is considered to be less tangible and more personal (Blau, 1964; Bacharach, Bamberger, and Vashdi, 2005). While conceptually distinct, these two types of help frequently co-occur in the workplace (Bamberger, 2009), such that the instrumental and socio-emotional benefits of receiving help are often intertwined (Lawler, 2001). Help-givers may perceive several potential benefits of providing help (Flynn, 2006), including: eliciting future in-kind reciprocation from receivers (e.g., Gouldner, 1960; Batson, 1998; Thibaut and Kelley, 1959); learning new skills and keeping up to date on the problems of other workers (Perlow and Weeks, 2002); enhancing their reputation within a work 
unit as generous organizational citizens who have the expertise that others need (Bolino, 1999; Sutton and Hargadon, 1996); enhancing their own self-image as generous and prosocial (Flynn, 2005; Grant, 2007); and, especially in the case of knowledge workers, bolstering their professional identities as people who can solve problems or provide new ideas (Chatman and Flynn, 2001; Elsbach and Flynn, 2013).

Potential costs to both help-seekers and help-givers center primarily on the time and energy expended or wasted in seeking and/or receiving help (e.g., Tyre and Orlikowski, 1994) or giving help (Perlow and Weeks, 2002; Bergeron, 2007; Mueller and Kamdar, 2011). In addition, seeking help also involves social costs (Lee, 1997), such as admitting incompetence, acknowledging inferiority, and entering into a dependent relationship (Lee, 2002: 18). Repeatedly seeking help may also damage the help-seeker's self-esteem (Lee, 2002; Ashford and Northcraft, 1992; Morrison and Bies, 1991) or harm the seeker's image in the eyes of others by making the seeker seem incompetent or dependent (Nadler, 1998). Moreover, seeking help may mean that the seeker must repay such help in-kind at a later time; receivers taking on obligations to reciprocate will eventually incur the costs of help-giving (Gouldner, 1960; Flynn, 2006). Besides the costs of their time, potential help-givers also may lose status or feel embarrassed if they are not able to effectively solve the problem, and they may be seen as ungenerous if they decline requests or do not provide enough assistance to meet receivers’ needs (Flynn, 2006). These costs (on both sides) lead helping to become stigmatized in many organizations (Grant and Patil, 2012; Hargadon and Bechky, 2006), such that help-seeking is normatively discouraged, making it even more costly.

To the extent that the existing theoretical literature considers processes involved in helping, those processes focus on the initial cost/benefit analyses that help-seekers and -givers make in 
deciding whether to enter into a helping episode. Many theorists have addressed individuals' decisions to seek help. For instance, Anderson and Williams’s (1996) model of help-seeking proposes that help-seekers (1) perceive task demands, (2) weigh the costs and benefits of seeking help, (3) seek help, and then (4) either receive or do not receive it. Other help-seeking process models propose similar stages, adding moderators such as individual differences (Flynn, 2006; Bamberger, 2009), the relationship between the seeker and the giver (Hofmann, Lei, and Grant, 2009), and organizational or work-group norms (Ehrhardt and Naumann, 2004; Grant and Patil, 2012). Models of the help-giving process pick up where models of the help-seeking process leave off-with a potential help-giver confronted with an explicit request from a help-seeker (Flynn and Lake, 2008). The literature on help-giving, parallel to that on help-seeking, focuses on determinants of the giver's decision to comply with a helping request.

In our view, although the prior helping literature presents a deep and nuanced picture of the determinants of helping, it has three important limitations. First, and most fundamentally, the existing literature does not address what happens during the helping episode itself—after the agreement (or refusal) to help. Insufficient attention has been paid to the interaction between givers and receivers; the story ends with a request for help being accepted or denied (e.g., Grant and Dutton, 2012; Batson et al., 2002). Indeed, nearly all empirical studies of organizational helping focus only on the initiation of a helping episode or its consequences; similarly, theories of helping are largely silent about what happens after a giver decides whether to help. The dynamics of the helping episode itself remain unexplored.

Second, few papers consider both the giving and the seeking of help; the two literatures have remained largely separate. Flynn's 2006 theoretical paper on subjective evaluations of help in organizations stands out as one of the few that integrates the literatures on help-giving and help- 
receiving and, as such, represents a significant advance. Taking a social exchange approach to the initiation of helping episodes, Flynn examines the costs and benefits of helping from both perspectives and considers the two-sided decision-making that occurs. However, this two-sided approach is rare.

Finally, although the literatures on both sides of the helping story have illuminated much about the cognitive processes that determine whether helping happens, they are limited by that cognitive approach. Few researchers or theorists have deeply explored the emotional or interactional processes that might also come into play (Lawler, 2001).

\section{The Helping Process: How Helping Happens in Organizations}

Not only does most prior research implicitly assume that the most important question about organizational helping is whether it happens_-ignoring the dynamics of how it happens_-but it also implicitly assumes that all helping is actually helpful, as long as the giver accedes to the seeker’s request. In Flynn’s (2006: 166) view (as in most of the existing helping literature), “successful episodes” are "requests for help that are fulfilled.” Little consideration is given to the possibility that helping attempts may often be unsuccessful. For example, within the organizational citizenship behavior (OCB) literature, there is a robust stream of research on the value of helping. This research has focused on the overall level of helping and on the generally positive link between the level of helping and group or organizational performance (e.g., Podsakoff et al., 2009). In defining helping as a behavior by which "individuals positively affect others” (Mossholder, Richardson, and Settoon, 2011: 33), a behavior that "promotes the effective functioning of the organization” (Organ, 1988: 4), OCB research has been relatively silent about the potential downside of helping (Bolino, Turnley, and Niehoff, 2004; Bergeron, 2007). 
We propose that a uniformly positive view of helping limits the development of theory, because it may well be presenting only half the picture. It also limits the ability of research to inform practice. The current literature leads to the implication that more helping in organizations is better, as long as sufficient time is available for helping. But this focus on quantity ignores the potentially significant contingency of the quality of helping. Conceivably, helping could do more harm than good if what happens during the helping episode undermines work progress or deters help-givers or -receivers from entering into future helping episodes.

This focus on the quantity rather than the quality of help provides an additional argument for exploring the helping process at the episodic level. Not only do we need to understand what happens after the initial decision by the help-giver to engage in the process, but we also need to understand how helping works effectively (when it works) and what derails it (when it does not). Although a few broad qualitative studies of helping in organizations do exist, none has sought to examine the helping interaction for process elements that might lead helping episodes to succeed or fail. Instead, these studies consider help beyond the episodic level, examining how help is influenced by culture (Perlow and Weeks, 2002), professional identity (Elsbach and Flynn, 2013), or work roles (Toegel, Kilduff, and Anand, 2013). Although Hargadon and Bechky (2006) describe how helping can contribute to collective creativity at the episodic level, they examine only successful helping episodes and do not address the helping process.

To begin filling the gaps we perceive in the literature, we focused our primary research question on how the helping process affects the success of a helping episode, as perceived by givers and/or receivers. In this effort to generate theory about the helping process, we go beyond the existing literature in four ways: (1) We empirically investigate the actions and experiences of 
both help-givers and help-receivers, because helping is, fundamentally, an interactional process ${ }^{1}$;

(2) rather than assuming that all helping episodes are successful, we assume that they can vary

widely in helpfulness; (3) we examine the helping process itself in detail, attempting to

understand how the dynamics between givers and receivers might lead to episodes being

perceived as successful or unsuccessful; and (4) we explore how both judgments and emotions enter into perceptions of helpfulness.

Working at the level of helping episodes (Flynn, 2006), we conducted an inductive, multimethod field study at an international design firm. The database we collected consists of 401 daily diary entries and 109 weekly interviews from four project teams, a separate sample of 42 critical incidents from 24 semi-structured interviews with help-givers and help-receivers, and observations. Qualitatively analyzing these data, we induce process models for both successful and unsuccessful helping episodes, and propose several critical factors that differentiate them.

\section{METHODS}

To investigate how the helping process affects the quality of help provided, we compared and contrasted helping episodes perceived as successful and unsuccessful. Our aim was to build theory on the helping process and on how that process influences givers' and receivers' perceptions of helping success. We took an inductive approach, in the spirit of grounded theorizing (Locke, 2001), to identify themes within our data. Because our data were organized at the level of the helping episode, we also used comparative case methodologies to assess the trustworthiness of our data (Eisenhardt, 1989). We believe that an inductive approach was called for because there has been very little description of the helping process in organizations or exploration of the assumption that helping is beneficial, making it a good fit for qualitative

\footnotetext{
${ }^{1}$ Because we investigated the helping process, which occurs after a help-seeker has become a help-receiver, we generally use the term "help-receiver" (or simply "receiver") instead of "help-seeker," which is more common in the literature.
} 
methods (Edmondson and McManus, 2007). Further, a qualitative approach helped us to capture the complexity of the helping process in order to “enliven theorizing” on helping (Locke, 2001: 97).

\section{Organizational Setting}

We collected data on helping episodes at the design consultancy Creative Design Firm $(\mathrm{CDF}){ }^{2}$ We chose CDF because design firms are known for having unusually high levels of structured helping (Sutton and Hargadon, 1996; Hargadon and Bechky, 2006). Further, CDF explicitly emphasized the value of giving and seeking help in its employee communications. The amount of helping at CDF allowed us to collect data on both extreme and prototypical helping episodes (Eisenhardt, 1989).

CDF is a leading design consultancy with multiple offices and hundreds of employees. ${ }^{3}$ This firm has a strong reputation for innovative designs; other organizations engage CDF for major, creative advances in product design, brand development, and strategy. The design consultancy sector became known for creating attractive and easy-to-use products for other organizations (e.g., Apple’s first computer mouse, Oral-B toothbrushes, and Reebok’s pump shoe (Hargadon and Sutton, 1997; Hargadon and Bechky, 2006)). However, design firms are now also contracted to redesign the strategies and processes of other organizations (Edmondson and Feldman, 2006).

During our study, CDF assigned small project teams to create solutions for clients that were “desirable, feasible, and viable” (CDF Toolkit). Teams ranged in size from 2-13 members, and most engagements lasted 5-22 weeks. Team members were generally assigned to only one project at a time; however, team membership would occasionally shift between project phases. Each project progressed through a maximum of three phases, though most projects focused on

\footnotetext{
${ }^{2}$ All names of firms and people are pseudonyms.

${ }^{3}$ We do not present exact numbers of offices and employees because these details would likely reveal the identity of the firm to those in the field.
} 
only one or two. In Phase 1, teams conducted interviews and observations of analogous products and services to better understand the domain of a given project. For instance, a team working on redesigning a diaper studied quick costume changes during theater productions for inspiration. In Phase 2, teams were asked to "translate what you heard from people into frameworks, opportunities, solutions, and prototypes,” by abstracting themes from their field research, then honing in on a few potential designs and prototypes (CDF Toolkit). In Phase 3, teams synthesized more detailed plans and engineering to create more final prototypes, documentation, and potential implementation plans.

Seeking and giving help from outside the core team was encouraged at many stages of the CDF process. Teams routinely invited CDF designers from outside their team to attend two types of help-giving meetings: (a) brainstorms, in which help-givers collaborated with team members in generating as many design or research ideas as possible, and (b) design reviews, in which team members presented nearly finished designs, and help-givers offered feedback and suggestions. Teams held at least one brainstorm per project, and one design review per phase. Some project teams had assigned "Project Mentors," who were supposed to make themselves available to help teams when needed and to check in periodically (although this did not always happen in practice). Last, some designers participated in informal "Interest Groups,” in which designers from similar functional backgrounds (e.g., mechanical engineering and interaction design) would meet to discuss functional issues in their projects or to share technical knowledge.

\section{Data Collection}

Consistent with recommendations to develop theory by iteratively collecting and analyzing multiple sources of data (e.g., Eisenhardt, 1989; Locke, 2001), our data collection proceeded through three major phases over a two-year period: (a) preliminary interviews and observations, 
(b) daily questionnaires and helping diaries from four project teams, with weekly interviews based on those daily responses, and (c) semi-structured critical incident interviews about successful and unsuccessful helping episodes. Throughout the study, we continued observations and informal interviews with CDFers, as well as reviewing archival documents (i.e., employee handbooks, CDF memos, project descriptions, and e-mails). Although the basic structure of the diary and interview questions was similar throughout the study, we refined our methodology in response to emerging themes in the data and informants' suggestions over the course of the study.

Informants. Overall, we interviewed, observed, and/or collected daily diary data from 69 CDFers (23 female, 46 male). Of those, 51 were designers, 10 were upper-level managers (including partners, design directors, and unit heads), and 8 worked in administrative roles. Informants in our study had worked at the firm for an average of 6.7 years $(S D=5.63)$ and were on average 35.2 years old $(S D=8.94)$. Most CDFers had a background in engineering or industrial design; others had backgrounds in communication design, life sciences, business, or the social sciences.

Phase 1 data collection. During Phase 1, we conducted on-site observations and informal interviews at a CDF office in a large U.S. East Coast city over a four-month period. Our goals were to gain a deep understanding of the context, to forge relationships with informants, and to give us a better understanding of the forms of helping common at CDF, as well as how to collect data about them. After describing our research interests to the leadership team, we visited their office on 21 occasions, focusing on days during which informants suggested we were likely to observe helping episodes. Overall, we observed five project team meetings (including brainstorms and design reviews) and five "Interest Group” sessions, as well as other meetings 
and office events. During Phase 1, we spent roughly 36 hours observing on-site and kept detailed field notes. We also reviewed archival documents, such as booklets designed to orient employees, client proposals for the projects we observed, and past internal documents and memos about improving access to help at CDF.

During Phase 1, we also developed our method for Phase 2 by suggesting questions and formats for the daily diary questionnaire, and adjusting them based on feedback from informants. We also conducted five of the critical-incident interviews described in Phase 3. After Phase 1, we were comfortable with the "lingo" used in the office and felt confident that we were asking questions in ways that made sense to CDFers.

Phase 2 data collection. During Phase 2, our data collection focused on four project teams from that East Coast office: Canadian Health Works, Pharma Process, Auto Strategy, and Medical Device. (See Table 1 for more details.) We selected these teams because they were representative of the variation in the types of clients and projects at CDF, we could follow the teams' progress throughout their projects, and all members agreed to participate in our study.

[Insert Table 1 here]

The four teams completed daily diaries about help they received on their project work, and also participated in weekly interviews based on those diaries. We chose the combination of diary entries and structured interviews for several reasons. First, consistent with Bamberger's (2009: 88) call for diary studies of help-seeking in organizations, we wanted to capture "the complex ‘tango' between help-seekers and potential providers.” Further, as suggested by prior studies of social support in families (e.g., Bolger, Zuckerman, and Kessler, 2000) and daily experiences of work (Amabile et al., 2005), we believed that the diary methodology would help to minimize memory issues and retrospective biases, while collecting representative variation in the types and 
success of helping episodes within a project.

To collect daily diary entries, we adapted the Electronic Event Sampling methodology (Amabile et al., 2005; Amabile and Kramer, 2011), which we used in conjunction with mobile phone SMS (text) messages and weekly interviews. At the end of each work day, team members received an SMS on their mobile phone, in which they were asked to give very brief open-ended responses to describe: (1) what work they performed regarding a specific team project, (2) what help (if any) they received on this project and a Likert-scale rating (7-point scale) of how helpful that episode had been, and (3) what help (if any) they needed that they did not receive. ${ }^{4}$ We conducted an initial training session with each team and provided written instructions for keeping the diary.

At the end of each week, the second author conducted private, semi-structured interviews with team members. Each team member interview lasted 10-45 minutes and covered the details of the episodes they had reported during the week. After catching up on what was happening in the project in general, the interviewer read the member their diary entries chronologically. For each entry, she asked "What happened and who was involved?” to elicit more details about what happened during the episode. If the informant did not mention it, she then asked about how the episode was initiated, probing for details about what cues were used to assess what help was needed. She then confirmed the rating of helpfulness from the diary entry and asked why they gave the rating they did.

Also at the end of each week, the second author conducted interviews with other CDFers likely to help the team (e.g., project mentors and client-relationship managers). These help-givers

\footnotetext{
${ }^{4}$ We had originally envisioned Phase 2 of data collection as the basis for a larger-scale quantitative study of the interplay between helping and creativity, motivation, affect, and work progress, using qualitative analyses and data in a supporting role. Thus, we also collected quantitative ratings of creativity, intrinsic motivation, affect, and work progress. However, our emerging insights from both Phase 1 and Phase 2 led us to focus more on the role of the helping process and to add Phase 3 to our data collection efforts.
} 
(who did not keep daily diaries) were asked to recall episodes in which they helped team members with the focal project during the week and how helpful they felt they had been during each episode. To protect the confidentiality of team members, the helpers were not reminded of helping episodes that were mentioned by team members.

Overall, of the 233 helping episodes in our Phase 2 data, 61 episodes featured data collected from more than one informant (26.2 percent); 33 of those contained both the perspectives of givers and receivers (14.2 percent). The relatively small proportion of episodes with both giver and receiver perspectives is due to the wide variety of helpers that team members drew on. However, we found extremely strong correspondence between the multiple accounts of each episode (i.e., no direct contradictions about the helping process and similar perceptions of help quality). These multi-perspective episodes thus helped us establish the trustworthiness of our single-perspective data and provided a unique window into helping interactions without compromising the confidentiality promised to our informants.

During data collection for our last two teams (Auto Strategy and Canadian Health Works), we determined that we were not seeing important new variation in the helping events reported nor the process by which these events unfolded. We thus concluded that we had reached theoretical saturation (Eisenhardt, 1989) via this method and did not recruit additional teams.

Phase 3 data collection. Based on the themes emerging from Phases 1 and 2, we wanted to gather more details on how aspects of the helping process led informants to deem the episodes successful or unsuccessful and to explore whether more extreme cases existed than those we had observed during Phases 1 and 2. We thus collected critical-incident interviews (Flanagan, 1954) in the firm's largest office, housed in a major West Coast city. This also allowed us to see whether our "hunches" (Locke, Golden-Biddle, and Feldman, 2008) from Phases 1 and 2 were 
transferable to a different office and to a wider variety of functions and projects.

We recruited informants by asking CDFers in explicit helping roles (e.g., design directors and administrative support staff) to participate, and by sending an all-office e-mail inviting CDFers to be interviewed about their experiences with help. Twenty-four 45-100 minute critical incident interviews were conducted (including five collected during Phase 1). In the interviews, we asked informants to describe in detail two separate incidents: one in which they successfully helped a project team (or received especially helpful help), and one in which they tried to help but felt they were unsuccessful (or received help that was not very helpful). Because we viewed perceptions of helpfulness as a key part of the phenomenon we were studying, we used informants’ classifications to identify episodes as successful or unsuccessful.

We first asked informants to choose whether they would describe episodes of giving or receiving help. Fourteen informants described episodes of giving help, and ten described episodes of receiving help. We asked about half of the informants to start with a successful episode, and the other half to start with an unsuccessful episode. We asked givers to "think of a specific incident at CDF when you successfully [unsuccessfully] helped a team. This incident should have the following features: (a) you remember the incident well (so it probably happened recently), (b) you were not a core team member (at least not when this incident occurred), (c) you interacted directly with team members (rather than exclusively with the client or behind the scenes), and (d) you believe that what you did helped [did not help] the team.” Following the giver's thorough description of the first episode (either successful or unsuccessful), we asked for an episode of the opposite type. We used parallel prompts for those in the receiver role, but specified that informants should recall episodes in which they were core team members. 
To attempt to minimize retrospective biases, we drew on Behavior Event Interview methodologies (McClelland, 1998), in which interview questions focused on respondents' specific observations, thoughts, and feelings during the incident (i.e., "Set the scene for mewho was in the room?," "What did they say to you?," and "What were you thinking, then? How did you feel?”). Six interviews covered only one episode in sufficient detail, leaving a total of 42 episodes for analysis—21 successful episodes and 21 unsuccessful episodes.

\section{Data Analysis}

Throughout our analyses, we took an inductive approach to developing our process models. We alternated between immersing ourselves in our data and discussing emerging themes and theoretical structures (e.g., Locke, 2001). We focused on helping episodes-the interaction between a help-receiver (who is a member of a project team) and a help-giver (who is external to the team) around a bounded set of the receiver's issues. Helping episodes, by definition, had at least two actors: a help-giver and help-receiver. Some episodes featured multiple receivers and/or givers; for instance, brainstorms and design reviews were occasions on which multiple givers were invited and the whole team was present to receive the help. Other episodes were limited to one-on-one interactions, in which one member received help on behalf of the team. Episodes could vary in length from a few minutes to several days.

Preliminary analyses. During Phase 1, we held weekly meetings to discuss emerging hunches from our field notes (Locke, Golden-Biddle, and Feldman, 2008) and approaches to future data collection. During Phase 2 data collection, the first and second authors held weekly meetings to discuss emerging themes and potential areas to probe for in the weekly interviews. At the end of each Phase 2 project, we compared the most helpful and least helpful episodes and theorized what differentiated them within each project. We held two-hour debrief meetings with 
three of the four teams, during which we shared our understandings of the role of helping in their project and got the team's responses to them. After data collection with each team, the authors discussed in detail how themes from one team compared to themes from the other teams. During Phase 3 data collection, all three authors held brief daily meetings to discuss themes and methods, as interviews from the West Coast site were conducted over five consecutive days.

Main analyses. Our main analyses focused on data about specific helping episodes collected during Phase 2 and Phase 3. We compared and contrasted the episodes informants considered successful with those they considered unsuccessful. In Phase 3 critical-incident interviews, we operationalized successful and unsuccessful episodes based on informants' classifications in response to our prompts. In Phase 2, we used informants' helpfulness ratings to operationalize the quality of the episode reported in the diary and described in the weekly interview. We found 233 helping episodes in 401 diary entries; helpfulness ratings were missing from three episodes, yielding 230 episodes for which we had ratings. The mean helpfulness rating for these episodes was $5.39(S D=1.28)$ on our 7 -point scale, and only $20.4 \%$ of these episodes were rated at or below the mid-point of the scale (4). We operationalized unsuccessful episodes as those rated 1-4 ( $n=47)$ and successful episodes as those rated 6-7 $(n=121)$ on our seven-point scale. We felt this definition reflected well the distribution of helping success in our study; many of the events rated as 6 were considered extremely helpful and were the highest-rated events by that individual. Thus, we felt that restricting our definition of successful to only episodes rated as 7 would have omitted important data.

We analyzed all of our interview transcripts from Phase 2 and Phase 3 using both a temporally structured process perspective (Langley, 1999) and in-vivo coding, in which we iteratively created codes and combined them into higher-order theoretical dimensions (Locke, 
2001). Our initial temporal organization comprised pre-episode events, within-episode events, and post-episode events. Within each of these temporal categories, a coding team composed of the first author, the second author, and a research assistant not involved in data collection coded the data. The first and second authors began discussing themes in weekly meetings throughout Phase 1 and Phase 2, and all three authors conferred monthly to discuss emerging themes and adjust the interview focus during this time. After Phase 3 of data collection, the coding team held weekly or bi-weekly analysis meetings.

Initially, the coding team generated in-vivo codes, wrote case descriptions for each episode, and created memos based on the themes observed in the data (Locke, 2001). During our weekly meetings, we compared in-vivo codes, case descriptions, and memos to create provisional themes. We then iteratively used and adjusted these themes as coding continued. In taking a process perspective, we also paid careful attention to the timing and sequence of themes within episodes. The coding team also held three all-day theorizing meetings with the third author to refine our themes and process models; we held these meetings roughly two or three months apart. At each stage of our theory-building, we delved back into the data to search for evidence that contradicted our emerging models, as well as evidence that supported them. This process allowed us to refine the models.

\section{FINDINGS}

Our primary research question asked how the helping process affects the success of a helping episode, as perceived by givers and/or receivers. The development of process models of successful and unsuccessful helping led to two key discoveries. First, unsuccessful helping episodes were characterized by diagnostic incongruence, which we define as conflicting expectations about how the interaction will unfold and/or understandings of the project state. 
Second, successful helping episodes fostered diagnostic congruence via aligning practices enacted before or at the very beginning of an episode. Essentially, the primary difference between the two types of episodes was whether the two parties quickly established a shared diagnosis of the problem to be solved and how they would approach it.

We begin this section with two vignettes that illustrate the key differences between successful and unsuccessful helping processes. Successful helping episodes featured purposeful efforts to align givers' and receivers' understandings of the project and expectations for the episode, which fostered on-target help and smooth interactions. For instance, Kaya (R14) ${ }^{5}$ told us about an episode in which she was a member of a three-person team working on a project for a large bank (SportBank) sponsoring a national sports team. Rose, the project leader, felt the team needed outside perspectives as it worked to combine its research insights into conceptual themes. When she invited three potential givers via e-mail, Rose explicitly framed her expectations for the episode and her view of the project state, laying out precisely, "Here's what we've done and here's where we're at; here's where we're going and here's how we need your help.”

Rose engaged her entire team to prepare for the helping episode. She coached them to select key information to share with the givers before they arrived. In contrast to typical CDF design reviews, which take place in teams' project spaces, she reserved a conference room for this helping episode. She then had the team choose or create sketches and sticky notes summarizing their findings, and array them in the conference room in such a way that givers could peruse them quickly to get up to speed on the project.

\footnotetext{
${ }^{5}$ All names of people and companies are pseudonyms. We have also altered the details of projects to protect our informants' confidentiality. Quotations are labeled with an informant code that denotes the informant's role in the episode ( $\mathrm{G}=$ Giver; $\mathrm{R}$ = Receiver) and a unique identifying number.
} 
When the help-givers arrived, project leader Rose reiterated her expectations for the episode and made sure that both the team and the three givers understood them. As team member Kaya told us, both givers and receivers “came in knowing that it's not about critiquing ... it's more about bringing new ideas to the table.” The givers then examined the material the team had brought to the conference room and were quickly able to ascertain "what help was needed and what were the gaps in our thinking." Thus, the feedback they gave was "on point,” and the episode was free flowing and conversational. In the end, Kaya believed the episode was helpful because it helped the team move "forward faster;" they "got more concrete and threw away some things,” which made her feel more comfortable about the SportBank project’s progress.

In contrast, in unsuccessful episodes, diagnostic incongruence elicited a cycle of unwanted help, wasted time, and negative emotions. An example comes from one of the projects we followed in Phase 2 of our data collection, where the client, Canadian Health Works (CHW), was a large non-profit that had engaged CDF to identify new strategic initiatives to revitalize its mission and increase membership. Melissa (R10), the project leader, initiated this episode when she received a troublesome e-mail from the client. However, in seeking help, Melissa did not take the time to indicate what, specifically, she was seeking from Brad (G12) and Richard (G15), two more senior CDFers with experience in health care who had said they were available to help. “I e-mailed Brad and Richard about this e-mail from the client where they're saying they're worried about something," she said. "I was running out the door, so I forwarded them the e-mail and [said] 'Hey, I’m going to respond to this later, but I just want to get your input.”' Melissa failed to supplement this vague request with more specific information on the nature of the help she was hoping to get, and neither Brad nor Richard probed further. 
Due to this failure, Brad and Richard formulated their help without a clear notion of exactly what Melissa wanted. Not only did Melissa fail to provide Brad and Richard with background information on the nature of the client's e-mailed concern, but it soon became clear that neither helper had thoroughly read the forwarded e-mail with her vague request for “your input.” During his weekly interview with us, Richard said, in referring to Melissa's e-mail, “I haven’t had a chance to look at it too thoroughly.” Melissa told us that she had to buttonhole Brad about it en route to a meeting: "I brought it up to [Brad] in the car because he hadn’t read the e-mail yet." Brad himself later said, "Personally, now I wish I could spend more time with this team ... I was supposed to work with the team [but] at the last minute ... we had an emergency on another project."

When Melissa finally got responses from her helpers, their advice was much too general. "It wasn’t what I was looking for,” she said. “[Richard and Brad] were both taking it into more of that philosophical level, like, 'Oh, well I don't know, we could do this or we could do that' ... I was looking for more like concrete advice ... I wanted them to say, 'Tell them this and tell them that."”

In the end, Melissa did not use the input that she received from Richard and Brad; in fact, she felt that their conflicting advice impeded her work. As she described it, "[The help] might have impeded [the project] because they actually had differing opinions ... I just went ahead and kind of said what I was going to say to the client.” For his part as a giver in CHW, Richard complained that he had no indications of whether his advice had been helpful: "It can be hard to tell how helpful you are or even [how] counterproductive help can be ... The feedback loop is not always so great.”

\section{The Helping Process}


As these vignettes illustrate, unsuccessful and successful helping episodes unfolded according to very different processes. Importantly, the seeds of helping success and failure were sown in an episode's earliest moments. Successful episodes began with purposeful efforts to align givers' and receivers' understandings of what help was needed and the current state of the project. These aligning behaviors fostered diagnostic congruence—shared expectations about how the helping interaction would unfold and shared understandings about the project state. Diagnostic congruence on these two dimensions allowed actors to give and receive help efficiently and effectively, stimulating project progress through enjoyable—or at least anxietyreducing—interactions.

In contrast, unsuccessful episodes began with minimal setup or pre-work; givers began trying to help with little guidance from receivers or preparation beforehand. Soon after help was offered or requested, givers and receivers began to notice discrepancies between what sort of helping behaviors they and the other party believed were appropriate, or found that it was extremely time-consuming for the receiver to get the giver up to speed on the project state. As the episode proceeded, the parties became aware that they had incongruent expectations about the helping episode and/or incongruent views of the project; the giver's help missed the mark in some fundamental way. The combination of this "off-target” help and the discomfort in feeling misaligned with the other party elicited negative emotions and/or inhibited instrumental progress. These contrasting processes are depicted in Figure 1. In the remainder of this section, we contrast successful and unsuccessful episodes at each stage of the processes.

[Insert Figure 1 here]

Initiating. Although we did not observe differences between the unsuccessful and successful episodes in how the episode was initiated, we include initiating behaviors in our process models 
for the sake of completeness. Both types of episodes began when either the receivers sought help or the givers checked in with the receivers to see how things were going. Because these behaviors did not serve as differentiators, we do not discuss them further.

Aligning in successful episodes. Aligning practices included two activities that defined what kinds of help both parties expected, and updated givers on the current state of the project: (a) framing the interaction and (b) sharing key project information and artifacts (e.g., prototypes, drafts of presentations, and summaries of ideas). The presence of these practices was a key difference between successful and unsuccessful episodes in our data.

We define "framing" as receiver actions that specifically indicate the kind of help desired, the specific aspects of the project to be examined, the role that the giver will play in the episode, and/or the receiver's assessment of the project. Recall how in the SportBank episode, Rose explicitly outlined her expectations for a helping episode both before and at the beginning of the episode. In telling givers, “Here’s what we've done,” Rose helped givers avoid rehashing approaches the team had already tried. In telling givers explicitly, "Here's where we're going and here's how we would like you to help,” Rose clarified the team's current evaluation of the project, specifying what aspects of the project the team felt good about, and what aspects they were most receptive to changing. Beyond getting givers up to speed on the project, framing behaviors also delimited the episode's scope, allowing givers to focus on only a subsection of the project rather than spending time getting up to speed on its entirety. Framing the episode also fostered shared expectations about which giver behaviors would be most helpful during the episode. Indeed, successful episodes often began with receivers focusing givers on certain aspects of the project—rather than asking givers their views more generally as in the CHW episode—and making clear how receivers viewed their projects. 
A second key practice prevalent in successful incidents was sharing artifacts, defined as receivers providing givers with physical representations of the project (e.g., sketches, prototypes, presentations, or rough drafts) for their review. This helped orient givers to the receiver's current thinking and gave them something concrete around which to form their assessment of the quality of the project and where their help was most needed. Artifacts were typically shared before the episode began, or at the very beginning. For instance, in the SportBank episode, the team created and arranged artifacts in preparation for the helping episode. More commonly, receivers would e-mail draft presentations or sketches when seeking help; in projects focused on designing products, receivers would often show physical prototypes. Creating and sharing these artifacts not only allowed helpers to catch up on the project, but also clarified for receivers the kind of help they needed and clarified for givers the helping behaviors expected. It also may have helped to bridge givers' and receivers' disparate knowledge and perspectives, similar to the way in which "boundary objects" facilitate interactions across organizational groups (Carlile, 2002; Bechky, 2003; Stigliani and Ravasi, 2012), and likely created a focal object on which givers and receivers could focus mutual attention (Metiu and Rothbard, 2013).

In many successful episodes, framing and sharing artifacts occurred simultaneously and were mutually reinforcing. For instance, in an invitation to a design review, a receiver we interviewed attached a draft of his presentation and told givers what aspects of the presentation he felt good about and what aspects he was less sure of. In his words,

"[I] sent [the givers] the presentation and gave them a sense of what sort of input we were looking for ... At some level, you need to set expectations, like 'We're two weeks from the end ... don't come in expecting to throw it all away, because we've been working with the client, so we're feeling pretty good about this. But we need another CDF designer sort of sanity check on it.'” (R12) 
Significantly, help-givers were often more senior than help-receivers. Thus, framing practices typically involved more junior help-receivers giving direction to more senior helpreceivers. Further examples of the presence of aligning practices in successful episodes are presented in Table 2.

[Insert Table 2 here]

Lack of aligning in unsuccessful episodes. In contrast to the purposeful creation of shared expectations and mutual understandings in successful episodes, unsuccessful episodes seldom featured either framing or sharing. We found abundant evidence of a lack of aligning behaviors, which had a significant impact on subsequent aspects of the helping process.

First, in unsuccessful episodes, receivers and givers framed episodes inadequately; they did not explicitly discuss their expectations, or receivers were extremely vague about what they hoped to gain. For instance, in the CHW episode, all the guidance Melissa gave the givers was "I just want to get your input,” which Brad and Richard interpreted differently from what she intended. In other instances, givers and receivers met without any attempt to frame the interaction. For instance, a receiver told us about an episode in which he was leading a project and the CDF client contact for the project offered to check in with the team at the end of a workday. The team agreed to meet with her, but did not clarify the purpose of the meeting or share any information or materials ahead of time. As the receiver told us:

"We came back from a day of work and we're like, 'Oh, we're going to meet with [the giver] at like 4:30 or 5:00. Yeah. We could do that.' ... We didn't set expectations ... [The giver] had no idea what she would see ... we hadn't reviewed how to talk about it or where to start. ... We didn't have any presentation format to download to her because it was so immediate.” (R18)

This failure to explicitly discuss expectations for the episode led givers and receivers to express confusion about the purpose. In such instances, it appears that receivers framed the episode 
inadequately for one of two reasons. Either they assumed that the type of help needed was selfevident, or they themselves were uncertain about the kind of help that would be most useful. As one receiver told us, “I don’t know if my challenge was too specific or if I wasn’t specific enough or if I just didn't have things clearly enough in my head yet” (R13). (See Table 3 for further examples.)

[Insert Table 3 here]

Further, in unsuccessful episodes, receivers failed to share key project artifacts or information with givers, or givers failed to review them before helping. In the CHW episode, neither of the two help-givers thoroughly read the forwarded e-mail, perhaps in part because what they were supposed to glean from it was unclear. However, in other episodes like the one reported by R18 above and others in Table 3, receivers failed to share artifacts and instead tried to summarize the project verbally. Efforts to align understandings of CDF projects without sharing or reviewing artifacts were often time-consuming and frustrating, giving these episodes a slow start (see Table 3 for additional examples).

Diagnostic congruence in successful episodes. In successful episodes, aligning practices at the beginning of episodes helped foster diagnostic congruence on two dimensions. First, to have congruence, givers and receivers needed to get on the same page; they needed to establish shared expectations for the episode, including the particular dimensions on which help was needed and the boundaries of what givers were willing to give and receivers were willing to receive. Givers and receivers most commonly got on the same page via receiver framing. In the SportBank episode, Kaya (R14) emphasized that both parties "came in knowing” what the purpose of the episode was. Informants in other successful episodes similarly described these shared expectations, using words like "they knew what they were trying to get from me" (G11), or "they 
get it ... they respected [the] rules of the engagement” (R12). Further, informants were often able to clearly articulate the purpose of the episode. While references to "getting it" or "being on the same page” were common in successful episodes, participants often did not expand on this idea. (See Table 4 for additional examples.) As we will show, clearer evidence supporting the importance of shared expectations comes from their absence in unsuccessful episodes.

[Insert Table 4 here]

Second, diagnostic congruence required givers being up to speed on the project state, including the project goals, what work had been done, and what ideas had already been tried and dismissed. Because CDFers were aware that getting givers up to speed was a key cost of helping, they often made concrete efforts to facilitate this process during the episode. In the SportsBank episode, Kaya noted that "part of getting help was telling the story in a concise way,” and that, after givers listened to team leader Rose's framing of the episode and perused the conference room, they "knew ... what help was needed and what were the gaps in our thinking." In other episodes, receivers commented on how quickly givers understood the project state, while givers often noted how quickly artifacts and framing got them up to speed (see Table 4). Both framing and sharing artifacts allowed givers and receivers to feel that givers understood the project well enough to help, and that they had minimized the amount of time spent on this necessary, but costly, aspect of helping.

\section{Helping actions and the emergence of diagnostic incongruence in unsuccessful episodes.}

In contrast, the lack of aligning practices in unsuccessful episodes allowed diagnostic incongruence to emerge, which triggered a vicious cycle of off-target help, uncomfortable interactions, and wasted time. Often in these episodes, the giver started trying to help as soon as 
the episode started. Because diagnostic incongruence emerged concurrently with helping actions in unsuccessful episodes, we discuss these subprocesses together.

Expectation incongruence, off-target help, and role violations. In unsuccessful episodes, givers often offered help that receivers felt was "off-target,” either because it dealt with different aspects of the project from what receivers expected, or it was at the wrong level of detail. In the CHW episode, when Melissa received "philosophical" advice instead of the more concrete suggestions she had expected, she realized that the givers had failed to understand what she was looking for. In such instances, receivers' failure to clarify what they needed likely contributed to givers offering off-target help. (See Table 5 for further examples.)

[Insert Table 5 here]

Perceiving help as off-target led informants to realize that their expectations about the interaction were quite different from those of their counterparts. Reports that givers and receivers held incongruent expectations about what help was needed were a hallmark of unsuccessful episodes, which informants described accordingly: "We were seeing the tenor of the help in such different lights" (G19) or "It was unclear what [receivers] wanted from me” (G18). (See Table 6 for further examples.)

[Insert Table 6 here]

Incongruent expectations also led actors to behave in ways that violated the role expectations of their counterparts, which made interactions proceed uncomfortably. This could either take the form of givers overstepping the role receivers expected them to take, or receivers requesting something that givers felt went beyond their role. For instance, a receiver (the project lead) told us about an episode in which she requested help from a more senior designer who was familiar with the client. She had e-mailed a draft presentation to him, but she suspected he had not read it 
because he had been on vacation. On his first day back, the receiver had hoped to get the giver's feedback on a short summary of the proposed design she was planning to give to the client, though she did not tell him this explicitly. However, during the episode, the giver instead took the receiver's laptop and began changing the content of the design itself (rather than the summary), which she viewed as going beyond his help-giving role. As the receiver told us:

"When we went into the project space to write, I thought it would just be evaluating the text that we'd already written. But for [the giver], he lives in the world of, 'If I'm here, we're just starting from scratch.' ... While I was there for feedback, it was basically him typing [new content] up. ... [The giver] took my laptop and started typing what he thought [the content] would be. And so it turned into his content, not the team's. ... [The giver] hacked the project content ... and stepped on my toes ... All along [I thought], 'Wait, I'm the Project Leadmaybe I should step it up and try and take over.' But I'm not combative, like I can't tell someone, 'Hey, what's the deal? Fuck off, I'm capable of this.' ... So I let him write it, while I sat there. He'd look at me and ask 'Is that what we think?' And I'm like, 'Sure, that's what we think."” (R15)

Violations of role expectations could also take the form of receivers making requests of givers that contradicted what givers construed as the bounds of their roles. In these instances, givers expected to contribute their ideas to a design or project, which was a central value at CDF, but receivers asked for more trivial contributions. For instance, a help-giver (G19) told us about a time she had been asked to help design a communications strategy for a new organization. She did not explicitly discuss her role with the receiver, but felt that the receiver "would be really remiss in not knowing ... when you work with [people in my role,] it's like we're your trusted advisor, like we're your strategic advisor ... We're more of a consultant than like a secretary.” However, the giver felt that the requests she received were more consistent with a secretary role:

“I really didn’t like the dynamic of my giving help and her receiving help because we were seeing the tenor of the help in such different lights. ... [The receiver] was really directive ... she came off as really confident and telling me what to do. ... She was pretty micromanaging ... like, 'Did you get the laundry, like, did you wash the socks?'-conveying distrust or conveying that 'I have to be in control here. I'm managing this, you're here to help me.' That was the dynamic that was in place. ... I snapped one day and [said,] 'I don't like this ... What I'm feeling from you is that you want me to check phone numbers, but where I 
think I can really provide value is in helping you to discover the person that is going to be most receptive to your message."” (G19)

This led the giver to eventually have a heated argument with the receiver, and left her feeling that her attempts to help had been unsuccessful. Both types of role violations described above led informants to view their counterparts as inconsiderate or unappreciative, and made the interaction proceed uncomfortably (see Table 6 for further examples).

Project state incongruence and trouble getting up to speed. Diagnostic incongruence could also manifest as asymmetrical views of the project state, including what work had already been done on the project, the quality of that past work, and how much work could realistically be accomplished before a deliverable. Informants described project state incongruence with statements like "I had trouble figuring out what it was about just by looking at it” (G18) or "they weren’t deep enough into what we were thinking about” (R13). (See Table 6 for further examples.)

Informants often realized that project state incongruence was present when it took too much time to get givers up to speed on the project, which prevented moving on to topics that needed the most attention or led to off-target help. Because people in unsuccessful episodes seldom sent or reviewed artifacts, the initial part of the helping interaction was spent briefing the giver on the details of the project. Because most CDF projects were complex, the process of getting givers up to speed sometimes took much of the time allocated to the episode. As a senior designer put it, "You bring in an outsider and have to bring them all the way up the learning curve with you, and that can use up all the time you have” (G24).

Even when this process succeeded in getting givers up to speed, the parties were frustrated at how long it took. For instance, one receiver recounted an episode in which he was a member of a 
team that received a large number of offers to help in the form of givers "dropping in" unexpectedly to their project space. As he told us:

"It felt like we had to start over every time a person came in because we had to bring them into where we were. ... [Givers would] come ... and were hearing it for the first time, and [would say], 'Oh, I thought of a brilliant idea!' [but we would think], 'We did that five times already.' ... People just kept drifting in and would suggest things that we had already processed and moved on from. ... God, it was hard, hard work. I was really exhausted by it, and frustrated by it.” (R04)

In this episode, the difficulty in bringing givers up to speed led to redundant suggestions, which wasted time and frustrated the receivers. Overall, episodes that focused on merely getting others up to speed were seen as having marginal value, which engendered dissatisfaction, frustration, and a perception that the attempted help was unsuccessful.

Project state incongruence also manifested as asymmetrical understandings of project quality. Most commonly, this took the form of receivers feeling good about their progress, but givers being more concerned about it. Often, receivers perceived episodes as unsuccessful when givers criticized their current approach without suggesting any clear action steps or providing any meaningful guidance—even if receivers felt the criticism was valid. CDFers referred to this phenomenon with dread as the "Swoop and Poop." As one senior CDFer described it:

“These young project teams don’t even feel like they have enough access to [senior designers'] time. What ends up happening is a senior person will come in and do a 'swoop and poop.' [The giver will] swoop in and poop on my project, and then [the receiver thinks], 'Oh my God, what am I going to do now?'” (G24)

In Swoop and Poops, givers criticized designs without making the basis of their concerns clear to receivers or suggesting a potential course of action. For instance, one receiver told us about an episode in which he sent a draft of a presentation to another CDFer who worked with the same client, but was not on his team. The receiver's intention was to get general design 
feedback and to keep the helper informed. However the giver swiftly offered unexpected

criticism without making any meaningful suggestions for improvement. As the receiver told us:

"[The giver's feedback] basically was editorial comments without suggestions .... The substantive feedback she was giving us was super distracting. ... [I thought,] 'Where's this feedback coming from? Are we talking about punctuation, grammar, and spelling, or are we talking about content?' ... [I thought she should] suggest something that would be less vague. Because that feedback was vague. ... [I wish I had said to her,] 'Like, help me. Either help me or get the fuck out of the way. ... Don't undermine my confidence and then walk out of the room.' ... You can't walk into a room, tell them that there's a stinking fish, and walk out.” (R12)

In this instance, as in others described as Swoop and Poops, we do not know the extent to which the help was "objectively" valid. However, because givers did not convince receivers of the validity of their view of the project state, receivers felt givers had failed to properly understand the situation, leading them to discount the givers' assistance.

Helping actions in successful episodes. Helping actions in successful episodes proceeded much more smoothly. Here, establishing diagnostic congruence early in the interaction set the stage for giving and receiving help that was on-target and often enjoyable. Helping interactions at CDF proceeded in one of two ways. In most episodes, helping consisted of a synchronous interaction in which the giver and receiver collaborated to address the receiver's issue. Alternatively, a giver completed a subtask asynchronously, in order to reduce the receivers' workload.

Because receivers had already framed the episode and shared key artifacts, givers were able to efficiently provide on-target help, delivering on the dimensions and at the level of specificity that the receiver expected. For instance, in the SportsBank episode, Kaya pointed out that the "nature of the feedback” was immediately "on point," with givers making the kinds of suggestions she had expected. Because diagnostic congruence had been established early in successful episodes, CDFers were able to avoid time-consuming efforts to get givers up to speed, 
and instead moved quickly to what receivers most wanted to talk about. This led informants to describe successful helping episodes as “conversational,” by which CDFers meant that the interaction was comfortable and informal, with both parties collaborating and building on each other’s ideas. Kaya noted this, saying, “It was more of a dialogue, [with both parties asking,] 'What makes sense?' ... It was a really casual conversation.” A number of other informants noted the conversational nature of successful helping actions, observing that offering suggestions “generated a conversation” (G11) or that “there were things that they hadn’t thought about that surfaced and emerged from the conversation” (G23). Another help-giver emphasized the conversational nature of her successful episode:

“The next thing you know, we're all just popping off ideas. ... As often happens, I felt like there's a point where they've got the microphone and they're telling me, and there is a point where I'm reacting. And then there's a point where we're all working together to advance the concept. And what we come out with is materially different than the assumptions we made coming in.” (G28)

Similar to Hargadon and Bechky’s (2006) findings that helping is an important vehicle for collaborative creativity, our data revealed a theme of helping actions in successful episodes as free-flowing and collaborative conversations that generated ideas. (See Table 7 for further examples).

[Insert Table 7 here]

In some successful episodes, helping actions did not take place during the interaction between giver and receiver; instead, the giver completed a subtask asynchronously. In these instances, because receivers often saw only the result of the giver's labor, they seldom described specific helping actions. For this asynchronous help, more detailed data about this subprocess came from givers, who knew what they did to provide help. For instance, a giver (G17) recounted how he fixed the motor of a toy for another team. In these asynchronous episodes, 
givers and receivers interacted to initiate the episode and align their understandings of the work and responsibilities, but then often did not interact again until the work was complete.

Helping outcomes in successful episodes. Because givers offered on-target help and the interaction was typically conversational in successful synchronous helping episodes, CDFers perceived these episodes as generating instrumental progress, which also engendered positive emotions (Amabile et al., 2005; Amabile and Kramer, 2011). In the SportsBank episode, Kaya believed that the episode allowed the team to move "forward faster" because the team "got more concrete and threw away some things," which made her feel "more comfortable” about the project. In other episodes, instrumental progress manifested as solving a problem, changing receivers' thinking, or reducing the amount of work that receivers had to do. The presence of instrumental progress then improved receivers' affective state, while givers felt proud that they had aided someone else. For instance, one giver noted his positive emotions in observing a team's progress (and members' excitement) after he had helped: "I remember walking in ... and [thinking] 'Holy shit, this is really cool. This is exciting.' And I think that moment when everybody can see something and they're excited by it, it’s like, 'Okay, we're going to be fine’” (G10).

In other successful episodes, receivers were initially stressed or apprehensive. Because they felt supported or reassured during the episode, their negative affect was reduced (rather than their positive affect being increased). In a particularly poignant example, a project leader's extreme anxiety was significantly lessened thanks to a giver offering him support:

"I slept that night, whereas I wasn’t sleeping the previous nights. I think [it was helpful because of] the emotional support that he gave, and [saying,] 'I'm going to step in and work next to you.' It wasn’t just words, but he was ready to act. Gave me a lot of safety, him stepping in.” (R01) 
More commonly, receivers were reassured by a helping episode, making them confident that they were on the right path and could proceed without radically altering their approach. As one receiver told us, "[The giver] looked at our document and said great things about our work, which is great to hear before the [client] call” (R06). (See Table 8 for further examples.)

[Insert Table 8 here]

The positive outcomes associated with successful asynchronous helping were somewhat different. For instance, a receiver noted, “[The episode] was helpful for me because then I wasn’t doing that [part of the work]" (R17*). In a different episode, a giver remarked that "the team appreciated it because it's one less thing that they have to deal with” (G02). In these episodes, receivers' relief in reducing their workload was the primary emotional outcome, while reduced labor was the primary instrumental outcome. Givers, in turn, experienced positive emotions when receivers expressed gratitude (Grant and Gino, 2010). As one giver told us, he felt helpful because "the reaction I got from her [the receiver] seemed like it was worthwhile, like ... she's getting what I'm saying and ... reacting to [my suggestions] positively” (G18).

Helping outcomes in unsuccessful episodes. In contrast, the problems emerging from diagnostic incongruence often both inhibited instrumental progress and elicited strong negative emotions. Indeed, the majority of unsuccessful helping episodes in our dataset were marked by negative emotions. Not surprisingly, both receivers and givers were likely to assess outcomes negatively if they believed that the help did not lead to meaningful instrumental progress—-that is, if the help did not change receivers' thinking or solve their problems, or was not incorporated into the final design. For instance, in the CHW episode, Melissa noted that the help "might have impeded the project” because of the time she spent getting help she did not use, and she was also "annoyed” by the whole experience; Richard, for his part, was ambivalent about the episode 
because Melissa hadn't told him whether he'd been helpful or not. In general, when helping episodes did not generate substantial instrumental progress, both givers and receivers were frustrated that they had invested so much time for so little gain. (See Table 9 for further examples.)

[Insert Table 9 here]

Surprisingly, although givers and receivers used both instrumental and emotional outcomes to determine that a helping episode was a success, they were much more likely to rely on emotional outcomes to declare an episode unsuccessful—even if the help generated progress. Overall, we found three major sources of negative emotions in unsuccessful episodes. First, a lack of perceived instrumental progress appeared to preclude positive reactions; not a single episode that failed to help a receiver move forward was accompanied by positive emotions. However, even episodes with positive "objective” instrumental outcomes were seen as unhelpful when they left givers or receivers with negative emotions. For instance, one receiver told us, "[The giver] actually had some good suggestions in terms of the design, but it was the attitude he portrayed [that made me feel he] was not on my team” (R03).

Second, negative emotions emerged from violations of role expectations. Givers generally saw themselves as valuable sources of help, and they felt deflated or hurt if they received indications to the contrary. For instance, one giver reacted negatively when the receiver did not appear to want her suggestions during a meeting. Feeling that he didn’t value her input, she said, "I have more to offer ... and his mannerisms make it feel like a rejection ... [which] flattened [my] enthusiasm” (G23). In some episodes, the non-appreciation of help was implicit, when receivers failed to express gratitude. In other episodes, it was quite overt, when receivers expressed dissatisfaction with the help. For example, in an episode in which the receivers said 
they were unhappy with the help, one of the givers thought, "You've got to be kidding mewe've done so much ... I was feeling very frustrated” (G09).

Third, because receiving reviews and critiques on their ideas cut to the heart of CDF designers’ identities, harsh critiques were especially likely to elicit negative emotions. For example, one receiver said that the giver's attempts to help made her question her role as project lead and consultant. As she described it, "Right when he started giving me the face [a face that implied 'What the hell is this shit?'], I was self-conscious, like, 'Shit, what have I done?'” In her words, this made her feel "like a young female in the workplace being dominated by a male coworker, like I don't know what I'm doing ... And that was really frustrating because then I felt silly” (R15). In this and similar examples, receivers’ negative emotions arose from a combination of receiving critical feedback and believing that such feedback was unwarranted.

\section{DISCUSSION}

The existing literature on helping in organizations provides a rich picture of many of the potential costs and benefits facing help-seekers and help-givers (Bamberger, 2009; Flynn, 2006; Nadler, 1997). However, in its focus on how actors decide whether to initiate a helping interaction, previous research has remained silent about how helping actually happens. Our inductive study illuminates the dynamics of the helping interaction itself. We set aside the implicit assumption of most prior research that, if helping happened, the episode was a success. Rather, we investigated how behaviors during the helping interaction shape its success.

Our analyses enabled us to develop helping process models, showing how actors successfully—and unsuccessfully—navigated helping episodes. These models emphasize the interactional and socially constructed aspects of helping. Successful helping is marked by the early establishment of diagnostic congruence; these episodes begin with clear efforts to align 
expectations, which facilitate on-target and conversational helping, leading to instrumental progress and positive emotions. In contrast, unsuccessful helping begins without efforts to first align expectations and understandings, which allows diagnostic incongruence to emerge and persist as help is given and received. As a result, help is seen as off-target, uncomfortable, and/or a waste of time, as the episode fails to generate instrumental progress and triggers negative emotions.

\section{Theoretical Contributions}

This study contributes to the literature on helping in organizations, and related literatures, by discovering the role of diagnostic (in)congruence in helping success, examining help from a process perspective, highlighting the importance of timing in aspects of the process, and uncovering the prominent role of emotion in perceptions of unsuccessful helping.

Diagnostic (in)congruence. The central contribution of this study is the discovery of interactional influences on the success of a helping episode-in particular, the subprocesses of diagnostic congruence and incongruence. Diagnostic congruence, when established early in a helping episode, can set the interaction on a positive course; incongruence will derail it. In fact, not only was diagnostic incongruence pervasive in the unsuccessful episodes in our study, but not a single episode with evidence of diagnostic incongruence was deemed successful by our informants. These findings suggest that, beyond simply being a characteristic of unsuccessful helping, diagnostic incongruence alone is sufficient to undermine a helping attempt. We propose two mechanisms by which this occurs, which also explain the importance of aligning behaviors: miscoordinated actions and role violations.

First, project state incongruence makes coordination difficult; it slows the process of getting givers up to speed and leads givers to offer redundant or unwanted help. The literature on shared 
cognitions in teams provides a good theoretical lens through which to understand this dynamic (e.g., Klimoski and Mohammed, 1994; Huber and Lewis, 2010). Just as "representational gaps” prevent diverse teams from capitalizing on their diverse knowledge and perspectives (Cronin and Weingart, 2007), differences in project understandings prevented people in our study from seeing various problems and solutions in the same way. In contrast to the teams literature, however, gaps in task understanding in helping episodes must be overcome more quickly because helping episodes tend to be shorter in duration than teamwork; moreover, the gap is often larger because of the insider-outsider nature of the helping relationship. Because the receiver owns the project and its issues, he/she inherently knows more about the problem at hand than the giver. On the other hand, the giver may know more about the general problem domain or the particular client who presented the problem.

Second, incongruent expectations about the helping episode increase the probability that role and norm violations will occur because, since they involve extra-role behaviors (Organ, 1988), helping episodes decrease the extent to which actors can rely on in-role behaviors and routines. Prior research has shown that role construals affect people's understandings of what helping is (Morrison, 1994; Van Dyne and LePine, 1998; McAllister et al., 2007), what constitutes adequate assistance (Coyle-Shapiro, 2002), or what kind of reciprocity helping should engender (Toegel, Kilduff, and Anand, 2013). Our findings go further to suggest that, even when parties agree that an episode should be considered "helping," the boundaries of helping roles must still be negotiated in order to clarify what norms and behaviors are applicable. In CDF, when givers violated the social norms that typically shield receivers from identity-threatening criticism (Flynn, 2005; Elsbach and Flynn, 2013), such as in Swoop and Poops, or overstepped what 
receivers believed were the bounds of their roles, the effect on receivers was negative emotion and assessment of the episode as unsuccessful.

Aligning practices—-framing the episode and sharing artifacts—-helped narrow these gaps in understandings and expectations. Although it is not surprising that explicitly framing an episode allows an actor to orient others toward desired goals, it is surprising that the actors who could do this framing most effectively were the relatively lower-status help-receivers. Prior research on framing (Goffman, 1974; Snow et al., 1986) and sense-giving strongly suggests that it is organizational leaders who must frame ambiguous situations to create meaning and structure for subordinates (Maitlis and Lawrence, 2007; Podolny, Khurana, and Hill-Popper, 2005). In contrast, we found that the subordinate parties—-help-receivers—-were much more likely to frame successful helping episodes than were help-givers. Thus, while prior research suggests that helpreceivers tend to be perceived as lower status and are placed in a subordinate position by the helping interaction (Goffman, 1971; Flynn et al., 2006), we found that, paradoxically, successful helping was more likely when receivers behaved in ways usually associated with leaders, often directing and giving sense to those with higher status.

Sharing artifacts was also central in conveying information about the project; this behavior served as a complement to framing. There is considerable evidence that shared, task-related artifacts help focus mutual attention (Metiu and Rothbard, 2013) and offer a communal source of knowledge that can bridge disparate perceptions (Carlile, 2002; Bechky, 2003). Because prototypes, presentation decks, and illustrations were common across various CDF design groups, most givers felt comfortable critiquing a prototype or draft presentation shown to them. In contrast, it is very challenging to understand and help with such complex projects in the absence of physical artifacts, with only verbal information. Artifacts clarified the project state 
(i.e., whether a prototype worked or how polished a presentation deck was) but were not always sufficient to align expectations. Although sharing artifacts aided the process of getting givers up to speed, it was most effective when accompanied by guidance about which aspects to focus on and the areas in which receivers were most interested in receiving help. Thus, the two types of aligning practices—-framing the helping interaction and sharing artifacts—-were mutually reinforcing.

A process perspective. Our analyses led to a model of the interactional dynamics between givers and receivers through which the helping process unfolds. We believe that this interactive, process-oriented perspective adds considerably to the literature on help-giving and -seeking, and could yield more in future research. If we had studied only the experiences of givers or receivers, or studied only one part of the helping process, it would have been difficult to discover and adequately describe the crucial role of diagnostic incongruence in unsuccessful helping, or the ameliorative role of aligning practices in successful helping. Just as importantly, our model depicts successful receivers as far more than passive vessels who accept whatever help is given, an image implied by the existing literature. Instead, by proactively working to shape and align givers' expectations, successful receivers help givers help them. Our model suggests that receivers must be assertively proactive in orienting givers to the project and helping givers understand the kind of help needed. More generally, by including the actions and perceptions of both givers and receivers, the interactional process approach can serve as a platform for uniting the streams of research on help-seeking and help-giving, which have been largely separate in the literature.

The importance of timing. Previous helping research has shown that time can be an important determinant of whether a helping interaction will occur. If help-seekers or help-givers 
are so time-pressed that they do not believe the likely benefit will outweigh the cost of their time, they will not seek or give help (e.g., Perlow and Weeks, 2002). Our research goes beyond prior work, by showing that the timing of certain behaviors can be an important determinant of how a helping episode will unfold. Specifically, we found that it is crucial to engage in aligning behaviors and, thus, establish diagnostic congruence, early in the helping interaction. This finding is consistent with research emphasizing the importance of beginnings in teams (e.g., Gersick, 1989; Wageman, Fisher, and Hackman, 2009). In a qualitative study of project teams, Ericksen and Dyer (2004: 438) found that high-performing teams used more “comprehensive mobilization strategies” at the beginning of their work, which allowed them more time to develop a better understanding of the task and complete the work. In contrast, low-performing teams engaged in "limited mobilization strategies," which made them slower in launching and mobilizing, and which led them "down a vacuous path of accumulating confusion ... from which they never recovered.”

We propose that early aligning practices serve a function similar to comprehensive mobilization strategies. When givers and receivers quickly established diagnostic congruence, they had more time in which to give and receive help; the absence of aligning practices invited confusion and misunderstandings, during which valuable time was wasted. Further, we saw no evidence that diagnostic incongruence could be overcome once it emerged - the experience of wasting time and the negative emotions that resulted did not dissipate during the episodes for which we collected data. As depicted in Figure 1, diagnostic incongruence and ineffective helping formed a self-reinforcing cycle.

The role of emotion in perceptions of helpfulness. Our findings offer a more nuanced view of how actors perceive helpfulness, answering Flynn’s (2006: 140) call for a stronger 
conceptualization of subjective perceptions of helpfulness. We show that both givers and receivers use two primary cues to understand the extent to which an episode is helpful: their perceptions of progress made during the episode and their emotions during the episode, which can be mutually reinforcing (Lawler, 2001; Amabile and Kramer, 2011).

Most surprisingly, we found that the presence of negative emotion was sufficient to induce perceptions that a helping episode was unsuccessful even when instrumental progress occurred and/or the client was pleased with the outcome. These findings suggest that "tough love” or harsh criticism will inhibit a culture of helping even when the feedback improves work quality. Because helping is discretionary, givers and receivers must be especially mindful of the importance of emotion in these interactions. These findings underscore the pivotal role that emotion plays in social exchange (Lawler, 2001). They also fit theories proposing a general psychological primacy of negative stimuli and events (e.g., Baumeister et. al, 2001); this "bad is stronger than good” theory suggests that people are more attentive to, and more strongly influenced by, the negative than the positive.

\section{Limitations}

The generality of our findings is limited by the type of work and workers we studied. Because our study was conducted in a single knowledge-work organization, transferability to other organizations is a concern. While we believe that our investigation of unsuccessful episodes at an organization known for its strong helping culture provides a compelling rationale for taking seriously the notion of unsuccessful help, the nature of CDF's team-based project work, or the makeup of its workforce, may have affected the processes and types of help we observed. Thus, future research should investigate the extent to which our model holds in other contexts. 
Indeed, we believe that our models of the helping process are likely to apply most strongly to project work involving challenging and uncertain tasks. The teams we studied worked on creative and ambiguous tasks; the need to establish congruence may be lessened in contexts with more structured work and clearer performance metrics (Laughlin, 1980). Our models are also more likely to apply in contexts where workers care about the quality of their work, and with workers for whom the esteem of their peers is important. Many of the emotional dynamics we observed were likely due to the tight relationship between designers' ideas and their identity (Elsbach and Flynn, 2013). If people did not care about maintaining ownership of their own work (Baer and Brown, 2012), or did not care much about what their peers thought of their ideas, we would be less likely to see the dynamics we described. Further, these dynamics are most likely to be elicited in deadline-delimited work in which there is at least moderate time pressure. The costs of time spent aligning and helping are more likely to be salient under these conditions.

Second, some of our data was drawn from a single perspective on a dyadic or group phenomenon. It is certainly possible that givers and receivers can differ in their perceptions of a given helping episode and, in fact, such differences have been of recent interest to helping researchers (Flynn, 2006). However, we believe that individual perceptions of helpfulness are an important outcome in their own right; because helping is discretionary, actors must perceive its value for productive helping norms within a unit or organization to form or persist (Grant and Patil, 2012). Further, for the episodes in which we have data from multiple perspectives, we saw a great deal of similarity between different actors' perspectives; the challenges and processes described by givers and receivers were similar regardless of which role the individual played in the episode he/she described. Although very few of the episodes in our dataset had informants who offered discrepant evaluations of the episode, we did find during Phase 2 that givers and 
receivers would often mention different episodes during a given week. This suggests that discrepant evaluations of the importance of episodes could have been present.

\section{Future Directions}

This study's contributions were enabled by our inductive approach, which focused at the level of the helping episode and treated helping as a complex interaction between givers and receivers. We believe that this interactionist approach holds promise for future research examining the helping process more extensively. Given the findings of our study, we see a few arenas as particularly fruitful for future work.

First, researchers should investigate the extent to which the well-documented factors that influence whether help-seeking and help-giving occur also affect how helping happens. For example, time pressure has been shown to influence both whether people seek help and whether they give it when asked. However, there has been no systematic study of the effects of time pressure on the helping process. Given our discovery of the apparent hazards of failing to invest time in aligning behaviors at the start of a helping episode, it will be important to determine whether time pressure strengthens the relationship between aligning, diagnostic congruence, and helping success. And, given our discovery that poorly framed helping requests can result in an overwhelming volume of sometimes-conflicting suggestions, researchers would do well to consider how the sheer number of help-givers might influence outcomes.

Other situational, individual, and relational factors that appear in the help-seeking/giving literature might well have main effects or moderating effects on the helping process—-factors such as organizational culture (Grant and Patil, 2012), receiver or giver expertise (Cross and Cummings, 2004), and receivers' trust of the giver (Hofmann, Lei, and Grant, 2009). As new research is conducted, however, it will be important to avoid the assumption that strong 
individual differences in help-giving or -receiving competence fully explain the unsuccessful and successful patterns we observed. Virtually all help-givers and help-receivers whom we interviewed with our critical incident method were able to generate examples of both clearly successful and clearly unsuccessful helping episodes in which they had participated.

Second, much work will be needed to more systematically investigate the behaviors we identified that facilitate or impede successful helping. Most notably, given the centrality of aligning behaviors to diagnostic congruence, it will be important to understand in detail the conditions under which help-givers and -receivers will and will not clarify their expectations for the helping interaction and share information about the project state. We found that, in some unsuccessful episodes, receivers might have been aware they needed help but were unable to even articulate what the problem was. For example, one giver told us, "I think [getting help] becomes particularly challenging when you're in a stressful project situation of indeterminate state ... if you're stressed out and you're not clear where it's going, it's not as easy to ask for help and receive help” (G06). Thus, it seems that the teams that needed the most help may have been least likely to solicit it effectively. To understand why and how the helping process succeeds or fails, we will have to investigate these and similar phenomena.

Third, although we made headway in illuminating the indicators that actors use to assess the helpfulness of episodes in which they were involved, unanswered questions remain. For example, both help-givers and help-receivers used their negative emotions as an indicator of helpfulness to a surprising extent; episodes with positive instrumental outcomes were still seen as unhelpful when they left givers or receivers with negative emotions. In fact, client and superior evaluations of the project were seldom mentioned as important indications that an episode had been helpful. Might this be a more general phenomenon, whereby actors in an 
organizational helping episode discount positive signals from clients or superiors under conditions of strong negative emotionality about the episode? Or might this be specific to knowledge-work contexts like CDF, where those involved in projects often have such special expertise that they and their peers truly might be the best arbiters of success? Many CDFers did appear to feel that other CDFers were harsher (and more expert) in assessing design quality than clients were.

More generally, what is the relationship between the use of emotions and the use of instrumental progress assessments in evaluations of helping success? We did not find incidents where positive emotions were coupled with a lack of instrumental progress. Might it be the case that such episodes were simply not catalogued as "help” by our informants and, thus, may not have been reported in our study? Or could it be that knowledge workers cannot feel good about help they have given or received unless they see evidence of progress?

\section{Practical Implications and Conclusion}

Our study has a number of practical implications. For would-be receivers of help, our results strongly suggest that they should frame the episode and share artifacts in advance—-tasks that require some level of reflection and preparation before seeking help. Further, when working on a project, people should assume that they will, at some point, need help, and keep potential helpgivers up to speed on their progress. For their part, givers should ask receivers to frame episodes and share artifacts, which givers should carefully review, before trying to help. Givers should avoid the "Swoop and Poop” by being mindful of receivers' vulnerability and the potential of help to disrupt the project and, most importantly, by offering constructive suggestions in addition to critiques. At the organizational level, management should allow time for capable helpers to 
assist others. At CDF, part of the reason for the high frequency of helping was the organizational support for it, including formal "helper" positions, leader encouragement, and slack time.

At the most basic level, our findings underscore the costs of poorly executed helping. Helping is not always helpful (Higgins, 2001); it is a challenging and potentially costly process that needs careful attention, management, and training. In exploring how people navigate the helping process, our research illuminated how simple acts to align expectations and understandings can mitigate the costs of helping. However, it also underscores how easily the helping process can be derailed—even in the presence of strong norms for helping. Given that unsuccessful help elicits such strong negative emotions, the promise of a helping culture cannot be realized without careful attention to the process of helping. Beyond focusing attention on the helping process, we hope that our study inspires both researchers and practitioners to focus on promoting help that is actually helpful, as well as fostering the conditions under which employees view help positively and know how to help others help them. 


\section{REFERENCES}

Amabile, T. M., S. G. Barsade, J. S. Mueller, and B. M. Staw

2005 "Affect and creativity at work." Administrative Science Quarterly, 503: 367-403.

Amabile, T. M., and S. J. Kramer 2011 The Progress Principle: Using Small Wins to Ignite Joy, Engagement, and Creativity at Work. Cambridge, MA: Harvard Business School Press.

Ancona, D. G., H. Bresman, and D. F Caldwell

2009 "Six steps to leading high performing X-teams.” Organizational Dynamics, 383: 217-224.

Ancona, D. G., and D. F. Caldwell 1992 "Bridging the boundary: External activity and performance in organizational teams.” Administrative Science Quarterly: 634-665.

Anderson, S. E., and L. J. Williams 1996 "Interpersonal, job, and individual factors related to helping processes at work.” Journal of Applied Psychology, 81: 282296.

Ashford, S. J., and G. B. Northcraft 1992 "Conveying more or less than we realize: The role of impressionmanagement in feedbackseeking.” Organizational Behavior and Human Decision Processes, 53: 310-334.

Bacharach, S. B., P. A. Bamberger, and $D$. Vashdi

2005 "Diversity and homophily at work: Supportive relations among white and African-American peers.” Academy of Management Journal, 48: 619-644.

Baer, M., and G. Brown

2012 "Blind in one eye: How psychological ownership of ideas affects the types of suggestions people adopt." Organizational Behavior and Human Decision Processes, 118: 60-71.

Bamberger, $\mathbf{P}$.

2009 "Employee help-seeking: Antecedents, consequences and new insights for future research.” In J. J. Martocchio and H. Liao (eds.), Research in Personnel and Human Resources Management, 28: 49-98. Bingley, U.K: JAI Press.

Batson, C. D.

1998 "Altruism and prosocial behavior." In D. R. Gilbert, S. T. Fiske, and G. Lindzey (eds.), The Handbook of Social Psychology, 2: 282-316. Boston: McGraw-Hill.

Batson, C. D., J. Chang, R. Orr, and J. Rowland

2002 "Empathy, attitudes, and action: Can feeling for a member of a stigmatized group motivate one to help the group?” Personality and Social Psychology Bulletin, 28: 1656-1666.

Baumeister, R. F., E. Bratslavsky, C. Finkenauer, and K. D. Vohs

2001 "Bad is stronger than good." Review of General Psychology, 5: 323-370.

Bechky, B. A

2003 "Sharing meaning across occupational communities: The transformation of understanding on a production floor." Organization Science, 14: 312330.

Bergeron, D. $M$.

2007 "The potential paradox of organizational citizenship behavior: Good citizens at what cost?” Academy of Management Review, 32: 1078-1095.

Blau, P. M.

1964 Exchange and Power in Social Life. New York: Wiley.

Bolger, N., A. Zuckerman, and R. C. Kessler

2000 "Invisible support and adjustment to stress.” Journal of Personality and Social Psychology, 79: 953961.

Bolino, M. C.

1999 "Citizenship and impression management: Good soldiers or good actors?” Academy of Management Review, 24: 82-98.

Bolino, M. C., W. H. Turnley, and B. P. Niehoff

2004 "The other side of the story: Reexamining prevailing assumptions about organizational citizenship behavior.” Human Resource Management Review, 14: 229-246.

Borgatti, S. P., and R. Cross

2003 “A relational view of information seeking and learning in social networks.” Management Science, 49: 432-445.

Bresman, $\mathbf{H}$

2010 "External learning activities and team performance: A multimethod field study.” Organization Science, 21: 81-96.

Carlile, P. R.
2002 “A pragmatic view of knowledge and boundaries: Boundary objects in new product development." Organization Science, 13: 442455.

Chatman, J. A., and F. J. Flynn

2001 "The influence of demographic heterogeneity on the emergence and consequences of cooperative norms in work teams.” Academy of Management Journal, 5: 956974

Cohen, S. G., and D. E. Bailey

1997 "What makes teams work: Group effectiveness research from the shop floor to the executive suite.' Journal of Management, 23: 239290.

Coyle-Shapiro, $\mathbf{J}$.

2002 “A psychological contract perspective on organizational citizenship behavior.” Journal of Organizational Behavior, 23: 927-946.

Cronin, M. A., and L. R. Weingart

2007 "Representational gaps, information processing, and conflict in functionally diverse teams." Academy of Management Review, 32: 761-773.

Cross, R., and J. N. Cummings

2004 "Tie and network correlates of individual performance in knowledge-intensive work.” Academy of Management Journal, 47: 928-937.

Edmondson, A. C., and L. R. Feldman 2006 "Phase Zero: Introducing New Services at IDEO.” Harvard Business School Case: 605-069.

Edmondson, A. C., and S. E. McManus

2007 "Methodological fit in management field research.” Academy of Management Review, 32: 1155-1179.

Ehrhart, M. G., and S. E. Naumann 2004 "Organizational citizenship behavior in work groups: A group norms approach.” Journal of Applied Psychology, 89: 960974.

Eisenhardt, K. M.

1989 "Building theories from case study research." Academy of Management Review, 14: 532550.

Elsbach, K. D., and F. J. Flynn

2013 "Creative collaboration and the self-concept: A study of toy designers.” Journal of Management Studies, 50: 515544. 
Ericksen, J., and L. Dyer

2004 "Right from the start: Exploring the effects of early team events on subsequent project team development and performance.” Administrative Science Quarterly, 49: 438-471.

Flanagan, J. C.

1954 "The critical incident technique." Psychological Bulletin, 51: 327358

Flynn, F. J.

2005 "Identity orientations and forms of social exchange in organizations.” Academy of Management Review, 30: 737750.

Flynn, F. J.

2006 "How much is it worth to you? Subjective evaluations of help in organizations.” Research in Organizational Behavior, 27: 133-174.

Flynn, F. J., and V. K. Lake 2008 "If you need help, just ask: Underestimating compliance with direct requests for help.” Journal of Personality and Social Psychology, 95: 128-143.

Flynn, F. J., R. E. Reagans, E. T. Amanatullah, and D. R. Ames

2006 "Helping one's way to the top: Self-monitors achieve status by helping others and knowing who helps whom.” Journal of Personality and Social Psychology, 91: 1123-1137.

Gersick, C. J.

1989 "Marking time: Predictable transitions in task groups." Academy of Management Journal, 32: 274-309.

Grant, A. M., F. Gino

2010 "A little thanks goes a long way: Explaining why gratitude expressions motivate prosocial behavior.” Journal of Personality and Social Psychology, 98: 946955.

Goffman, E.

1971 Relations in Public: Microstudies of the Public Order. New York: Basic Books.

Goffman, E.

1974 Frame Analysis: An Essay on the Organization of Experience. Lebanon, NH: Northeastern University Press.

Gouldner, A. W.

1960 "The norm of reciprocity: A preliminary statement.” American Sociological Review, 25: 161178.
Grant, A. M.

2007 "Relational job design and the motivation to make a prosocial difference.” Academy of Management Review, 32: 393417.

Grant, A. M., and J. Dutton

2012 "Beneficiary or benefactor: Are people more prosocial when they reflect on receiving or giving?” Psychological Science, 23: 10331039.

Grant, A. M., and S. V. Patil

2012 "Challenging the norm of selfinterest: Minority influence and transitions to helping norms in work units." Academy of Management Review, 37: 547568.

Hackman, J. R., and R. Wageman

2005 "A theory of team coaching." Academy of Management Review, 30: 269-287.

Hansen, $\mathbf{M}$.

2009 Collaboration: How Leaders Avoid the Traps, Build Common Ground, and Reap Big Results. Cambridge, MA: Harvard Business School Press.

Hargadon, A. B., and B. A. Bechky 2006 "When collections of creatives become creative collectives: A field study of problem solving at work.” Organization Science, 17: 484-500.

Hargadon, A. B., and R. I. Sutton 1997 "Technology brokering and innovation in a product development firm." Administrative Science Quarterly, 42: 716-749.

Higgins, M. C.

2001 "When is helping helpful? Effects of evaluation and intervention timing on basketball performance.” Journal of Applied Behavioral Science, 37: 280-298.

Higgins, M. C., and K. E. Kram

2001 "Reconceptualizing mentoring at work: A developmental network perspective.” Academy of Management Review, 26: 264288.

Hofmann, D. A., Z. Lei, and A. M. Grant

2009 "Seeking help in the shadow of doubt: The sensemaking processes underlying how nurses decide whom to ask for advice." Journal of Applied Psychology, 94: 1261-1274.

Huber, G. P., and K. Lewis

2010 "Cross-understanding: Implications for group cognition and performance.” Academy of

Management Review, 35: 6-26.

Kahn, W. A.

1993 "Caring for the caregivers: Patterns of organizational caregiving." Administrative Science Quarterly, 38: 539-563.

Katz, D., and R. L. Kahn

1966 The Social Psychology of Organizations. New York: Wiley.

Klimoski, R., and S. Mohammed

1994 "Team mental model: Construct or metaphor?” Journal of Management, 20: 403-437.

Langley, A.

1999 "Strategies for theorizing from process data." Academy of Management Review, 24: 691710 .

Langley, A., C. Smallman, H. Tsoukas, and A. H. Van de Ven

2013 "Process studies of change in organization and management: Unveiling temporality, activity, and flow.” Academy of Management Journal, 56: 1-13.

Laughlin, P. R.

1980 "Social combination processes of cooperative problem-solving groups on verbal intellective tasks.” In M. Fishbein (ed.), Progress in Social Psychology: 127-155. Hillsdale, NJ: Erlbaum.

Lawler, E. J.

2001 "An affect theory of social exchange.” American Journal of Sociology, 107: 321-352.

Lee, $\mathbf{F}$.

1997 "When the going gets tough, do the tough ask for help? Help seeking and power motivation in organizations.” Organizational Behavior and Human Decision Processes, 72: 336-363.

Lee, $\mathbf{F}$.

2002 "The social costs of seeking help." The Journal of Applied Behavioral Science, 38: 17-35.

Locke, K. D.

2001 Grounded Theory in Management Research. London: SAGE Publications Limited.

Locke, K., K. Golden-Biddle, and M. S. Feldman

2008 "Making doubt generative: Rethinking the role of doubt in the research process." Organization Science, 19: 907918.

MacKenzie, S. B., P. M. Podsakoff, and $M$. Ahearne 
1998 "Some possible antecedents and consequences of in-role and extra-role sales-person performance.” Journal of Marketing, 62: 87-98.

Maitlis, S., and T. B. Lawrence 2007 "Triggers and enablers of sensegiving in organizations." Academy of Management Journal, 50: 57-84.

McAllister, D. J., D. Kamdar, E. W. Morrison, and D. B. Turban

2007 "Disentangling role perceptions: How perceived role breadth, discretion, instrumentality, and efficacy relate to helping and taking charge.” Journal of Applied Psychology, 92: 12001211.

McClelland, D. C.

1998 "Identifying competencies with behavioral-event interviews." Psychological Science, 95: 331339

Metiu, A., and N. P. Rothbard

2013 "Task bubbles, artifacts, shared emotion, and mutual focus of attention: A comparative study of the microprocesses of group engagement.” Organization Science, 24: 455-475.

Morrison, E. W.

1994 "Role definitions and organizational citizenship behavior: The importance of the employee's perspective." Academy of Management Journal, 37: 1543-1567.

Morrison, E. W., and R. J. Bies

1991 "Impression management in the feedback-seeking process: A literature review and research agenda.” Academy of Management Review, 16: 522541.

Mossholder, K. W., H. A. Richardson, and $R$. P. Settoon

2011 "Human resource systems and helping in organizations: A relational perspective.” Academy of Management Review, 36: 3352.

Mueller, J. S., and D. Kamdar

2011 "Why seeking help from teammates is a blessing and a curse: A theory of help seeking and individual creativity in team contexts." Journal of Applied Psychology, 96: 263-276.

Nadler, A.

1997 Personality and Help Seeking: Autonomous Versus Dependent Seeking of Help. New York: Plenum Press.
Nadler, A.

1998 "Relationship, esteem, and achievement perspectives on autonomous and dependent help seeking.” In S. A. Karabenick (ed.), Strategic Help Seeking: Implications for Learning and Teaching. Mahway, NJ: Lawrence Erlbaum Associates.

Organ, D. W.

1988 Organizational Citizenship Behavior: The Good Soldier Syndrome. Lexington, MA Lexington Books.

Perlow, L.

1997 Finding Time: How Corporations, Individuals, and Families Can Benefit from New Work Practices. Ithaca, NY: Cornell University Press.

Perlow, L., and J. Weeks

2002 "Who's helping whom? Layers of culture and workplace behavior." Journal of Organizational Behavior, 23: 345-361.

Podolny, J., R. Khurana, and M. HillPopper

2005 "Revisiting the meaning of leadership.” Research in Organizational Behavior, 26: 136.

Podsakoff, N. P., B. D. Blume, S. W. Whiting, and P. M. Podsakoff

2009 "Individual- and organizationallevel consequences of organizational citizenship behaviors: A meta-analysis.” Journal of Applied Psychology, 94: 122-141.

Schein, E. H.

2009 Helping: How to Offer, Give, and Receive Help. San Francisco: Berrett-Koehler Publishers.

Snow, D. A., R. B. Rochford, S. K.

Worden, and R. D. Benford

1986 "Frame alignment processes, micro-mobilization, and movement participation." American Sociological Review, 51: 464-481.

Stigliani, I., and D. Ravasi

2012 "Organizing thoughts and connecting brains: Material practices and the transition from individual to group-level prospective sensemaking." Academy of Management Journal, 55: 1232-1259.

Sutton, R. I., and A. Hargadon 1996 "Brainstorming groups in context: Effectiveness in a product design firm.” Administrative Science Quarterly, 41: 685-718.

Thibaut, J. W., and H. H. Kelley
1959 The Social Psychology of Groups. New York: Wiley.

Toegel, G., M. Kilduff, and N. Anand

2013 "Emotion helping by managers: An emergent understanding of discrepant role expectations and outcomes." Academy of Management Journal, 56: 334357.

Tyre, M. J., and W. J. Orlikowski 1994 "Windows of opportunity: Temporal patterns of technological adaptation in organizations.” Organization Science, 51: 98-118.

Van Dyne, L., and J. A. LePine 1998 "Helping and voice extra-role behaviors: Evidence of construct and predictive validity." Academy of Management, 41: 108-119.

Wageman, R., C. M. Fisher, and J. R. Hackman

2009 "Timing is everything: The importance of finding the right moment in leading teams." Organizational Dynamics 38: 192-203.

Weick, K. E.

1979 The Social Psychology of Organizing (Topics in Social Psychology Series). Reading, MA: Addison-Wesley.

Wuchty, S., B. F. Jones, and B. Uzzi

2007 "The increasing dominance of teams in production of knowledge.” Science, 316: 10361039. 
Table 1: Descriptive Statistics for Phase 2 Project Team Data

\begin{tabular}{cccccccc}
\hline Team Name & $\begin{array}{c}\text { Project } \\
\text { Length } \\
\text { (Weeks) }\end{array}$ & $\begin{array}{c}\text { Project } \\
\text { Work } \\
\text { Days }\end{array}$ & $\begin{array}{c}\text { Diary } \\
\text { Response } \\
\text { Rate }\end{array}$ & $\begin{array}{c}\text { SMS } \\
\text { Diary } \\
\text { Entries }\end{array}$ & $\begin{array}{c}\text { Team } \\
\text { Members }\end{array}$ & $\begin{array}{c}\text { Member } \\
\text { Weekly } \\
\text { Interviews }\end{array}$ & $\begin{array}{c}\text { Help- } \\
\text { Giver } \\
\text { Interviews }\end{array}$ \\
\hline $\begin{array}{c}\text { Canadian Health } \\
\text { Works }\end{array}$ & 7 & 33 & $65.2 \%$ & 86 & 4 & 18 & 4 \\
Pharma Process & 12 & 53 & $73.6 \%$ & 157 & 4 & 33 & 6 \\
Auto Strategy & 6 & 29 & $75.2 \%$ & 77 & 4 & 17 & 4 \\
Medical Device & 6 & 30 & $100 \%$ & 81 & 3 & 16 & 11 \\
\hline Totals & $\mathbf{3 1}$ & $\mathbf{1 4 5}$ & $\mathbf{7 7 . 5 \%}$ & $\mathbf{4 0 1}$ & $\mathbf{1 5}$ & $\mathbf{8 4}$ & $\mathbf{2 5}$ \\
\hline
\end{tabular}

\section{Table 2: Examples of Aligning Behaviors in Successful Helping Episodes}

\begin{tabular}{ll}
\hline Concept & Representative Quotations \\
\hline $\begin{array}{l}\text { Framing the } \\
\text { episode }\end{array}$ & "[We told the giver] what the main feedback we wanted was: Which one of these insights sounds stupid? ... \\
& Which ones to really hit home that sort of resonate with him, because we've been so immersed and clouded \\
& with the content.” (R03) \\
& "[The giver told the receiver], 'I will come to New York just to spend that week with you guys. And I can \\
& take out of your plate some of the pressure of the project work. So I’m going to be your crutch.”” (R01) \\
& "[The receiver] explicitly asked me to take care of a couple things... One was resourcing, to figure out how \\
& to fill [in for a couple of team members who left the project]. The other thing she wanted me to help [her] do \\
& is plan-help figure out the downstream scheduling” (G07) \\
& "So I was able to jump in and ... give him a really quick overview of our final interval from the last phase, \\
& and what the goals of the websites are that they’re working on.” (R17*)
\end{tabular}

Sharing artifacts "I tended to send [a potential help-giver] e-mail updates. That was actually one of those things where .... the letter you write is as helpful to you as it is to the other person. In having to summarize it in a way that ... makes efficient use of his time, I had to kind of boil it down to really the succinct key points and that actually helped me think about the project and think about like what are the key points here, right? So there was one of those things where just the act of doing that helped me right there.” (R22)

"[I] sent [the givers] the presentation and gave them a sense of what sort of input we were looking for." (R12)

"We had a wall [with] a mood board of different tones that we had used before. We brought it over from the project space ... [the giver, I, and another team member] were pointing to words, ones that we think would work, and which ones we didn't.” (R15)

$\mathrm{G}$ = help-giver; $\mathrm{R}$ = help-receiver. The number following the letter indicates a specific individual informant. Informants marked with '*’ participated in Phase 2 of data collection (project team daily diaries and weekly interviews).

\section{Table 3: Examples of Lack of Aligning Behaviors in Unsuccessful Helping Episodes}

\begin{tabular}{|c|c|}
\hline Concept & Representative Quotations \\
\hline \multirow[t]{3}{*}{ Lack of framing } & $\begin{array}{l}\text { “It was unclear what [the receivers] wanted from me ... The invitation wasn't set up as 'We're giving this } \\
\text { presentation, can you review it?' or 'We need your input on this particular thing.' It was like 'Can you come } \\
\text { in and just be part of this discussion? We're trying to figure this out.'” (G18) }\end{array}$ \\
\hline & $\begin{array}{l}\text { "Before our first meeting ... I knew he wanted stuff, photos and ideas. But I didn’t really know how he } \\
\text { wanted to shape the interactions.” (G23) }\end{array}$ \\
\hline & $\begin{array}{l}\text { "I never sort of got the sense of what we were doing ahead of time, why we were going to do it, how it } \\
\text { would all fit together ... [Helping attempts] would just happen [and we'd think] 'Oh, what are we doing } \\
\text { here?’” (R04) }\end{array}$ \\
\hline \multirow{3}{*}{$\begin{array}{l}\text { Lack of receiver } \\
\text { sharing or giver } \\
\text { reviewing } \\
\text { artifacts }\end{array}$} & $\begin{array}{l}\text { "I don't think I prepped [the giver] a ton, but I just said, 'Hey, I got a design review. We're releasing these } \\
\text { parts tomorrow, want to get your quick feedback before we shoot these off to get them made.”” (R03) }\end{array}$ \\
\hline & $\begin{array}{l}\text { "We'd send him e-mails, we showed him the content ... But, you know, on vacation you probably don’t } \\
\text { read anything ... I don’t think he did.” (R15) }\end{array}$ \\
\hline & "I probably should have read up on what they were doing." (G18) \\
\hline
\end{tabular}


"There was a lot of new stuff, but it's not fully visualized and that makes it hard to get feedback on." $\left(\mathrm{G} 10^{*}\right)$

$\mathrm{G}$ = help-giver; $\mathrm{R}$ = help-receiver. The number following the letter indicates a specific individual informant. Informants marked with '*’ participated in Phase 2 of data collection (project team daily diaries and weekly interviews).

\section{Table 4: Examples of Diagnostic Congruence in Successful Helping Episodes}

\begin{tabular}{|c|c|}
\hline Concept & Representative Quotations \\
\hline \multirow{5}{*}{$\begin{array}{l}\text { Shared } \\
\text { expectations } \\
\text { ("on the same } \\
\text { page") }\end{array}$} & $\begin{array}{l}\text { "They knew what they were trying to get from me ... They hadn't committed to any direction ... [so] really, } \\
\text { the purpose of the discussion was: Are there any good reasons right now to choose this path versus this } \\
\text { path?” (G11) }\end{array}$ \\
\hline & $\begin{array}{l}\text { "[At a different organization I worked at], you talk for } 30 \text { minutes and you basically just bitch about the } \\
\text { problem, and nothing comes out of it. But when [I] scheduled a half hour of [the giver's] time, he came } \\
\text { ready to help me out, with the intention of giving you something to move forward with.” (R20*) }\end{array}$ \\
\hline & $\begin{array}{l}\text { "In terms of helping teams, there are two parts, I guess. One is coaching; the other is like, 'Here's this piece, } \\
\text { can you take this piece and run with it? And this was kind of like, 'Take this piece and run with it."” (G17) }\end{array}$ \\
\hline & "She asked me to do that ... Basically, she delegated a chunk to me.” (G07*) \\
\hline & $\begin{array}{l}\text { "[The giver told me] 'I’m not here to change the project, I'm just here to help you. So you need to know } \\
\text { that.”' (R01) }\end{array}$ \\
\hline
\end{tabular}

Sharing project understandings ("up to speed")
"I think they did [send the giver the presentation ahead of time]. [The giver]'s pretty good at reading stuff at all hours of the night ... When we were reviewing it, he said, 'Oh yeah, that's going to tie into the next insight, right?’ And so [I knew] that he had read a little bit, had it in his head.” (R03)

"It was my first time coming in, so I was just trying to get up to speed. I knew a little bit about the project, but not that much. And so I sat with [the receivers] for about an hour. We talked through all of the different pieces that they were designing, and where they were with each of them. And most of what I did was actually ask why they were designing those pieces, and what the purpose was for each of them.” (G10*)

"We'd briefed [the giver] ... the week before; it was more sort of us talking to him about what the site's about and having him understand what's at stake. And then he understood it super-fast.” (R19*)

$\mathrm{G}$ = help-giver; $\mathrm{R}$ = help-receiver. The number following the letter indicates a specific individual informant. Informants marked with '*’ participated in Phase 2 of data collection (project team daily diaries and weekly interviews).

\section{Table 5: Examples of Helping Actions in Unsuccessful Helping Episodes}

\begin{tabular}{|c|c|}
\hline Concept & Representative Quotations \\
\hline \multirow[t]{3}{*}{$\begin{array}{l}\text { Help was } \\
\text { perceived as off- } \\
\text { target }\end{array}$} & $\begin{array}{l}\text { "I was latching onto something that [made me think,] 'I know you can change this ... but I'm not sure if } \\
\text { that's really going to help you or not' ... I kind of [wondered whether my advice] was what these guys } \\
\text { wanted to hear. Were they looking for something more like concrete ideas?” (G18) }\end{array}$ \\
\hline & $\begin{array}{l}\text { "[The giver] stepped in at a moment when we weren’t ready to present to her [and] sees unpreparedness or } \\
\text { struggling ... and tries to offer help at every level ... We gave her a fire hose of thought ... and as a result, } \\
\text { she jumped in to provide help at every level ... [She said things] like, 'I think those need to be written. You } \\
\text { bottom line thoughts need to be written slightly differently' ... I realized in hindsight I wanted very detaile } \\
\text { design feedback [instead].” (R18) }\end{array}$ \\
\hline & $\begin{array}{l}\text { “My style is just to go, 'Oh, we could do this or we could do that or maybe this will work.' And he just wa } \\
\text { like, 'Oh no-I’m concerned about that because ...' or 'This probably won’t work because ...' It was me } \\
\text { offering, him deciding.” (G23) }\end{array}$ \\
\hline
\end{tabular}

Interactions “[The receiver would] sit there and he'll stare at you. And so it doesn’t always feel like a conversation ... I proceeded just get quieter and quieter ... It's sort of taking the energy and deflecting it back towards the person who is uncomfortably trying to engage, and so it didn’t feel like this easy flow. It’s like bouncing a tennis ball off a brick wall.” (G23)

"I felt there was a little awkwardness ... because on the one hand, she is making a genuine, substantive contribution. And then on the other, she's not. So you can’t go back and be like, 'Your feedback sucks.' Because some of it doesn't suck.” (R12)

[The receiver felt he] "quickly got defensive” [ because he felt the giver] "was a little passive-aggressive" and had an "attitude” ... "It didn’t seem like he was on my team.” (R03)

$\mathrm{G}$ = help-giver; $\mathrm{R}$ = help-receiver. The number following the letter indicates a specific individual informant. Informants marked with '*' participated in Phase 2 of data collection (project team daily diaries and weekly interviews). 
Table 6: Examples of Diagnostic Incongruence in Unsuccessful Helping Episodes

\begin{tabular}{|c|c|}
\hline Concept & Representative Quotations \\
\hline \multirow[t]{3}{*}{$\begin{array}{l}\text { Expectation } \\
\text { incongruence }\end{array}$} & $\begin{array}{l}\text { "I still don't know ... what [the receivers] wanted ... I didn't get a sense that they understood exactly what } \\
\text { they were looking for ... [Although I had a long meeting with the Project Lead], I didn't want to commit to a } \\
\text { half-day thing. I was like, 'I can come help, but I’m not part of your core team and I don't want to commit } \\
\text { to jumping in and being part of your core team' ... I felt like I didn't want to commit to owning this whole } \\
\text { problem.” (G18) }\end{array}$ \\
\hline & $\begin{array}{l}\text { "I guess maybe in the beginning [of] any design review, you have to kind of be ready for feedback [and } \\
\text { say] in the beginning, 'Hey, guys, this is rough ... so there are some spots in here that I recognize that are } \\
\text { not as robustly designed. But I've been doing it with the amount of time that I have, with this deadline' ... I } \\
\text { think clearly trying to set that expectation up front [would have been better].” (R03) }\end{array}$ \\
\hline & $\begin{array}{l}\text { "[The giver] is great ... she's smart and a good person. I think I was a little blind to how unhelpful she was } \\
\text { being and how we weren’t dealing with it well. We just kept giving her a reason to be concerned ... We } \\
\text { should have just given her the top line confidence that everything was smooth and not shown her the guts. } \\
\text { And we showed her a bunch of the guts and she was like, 'Oh my, like is this team ready?' ... We should } \\
\text { have drawn a line of expectation and held that line. Even [saying something] like, 'We're not going to show } \\
\text { you behind this line because it's just not ready.”' (R18) }\end{array}$ \\
\hline
\end{tabular}

Project state "It was kind of like just jumping into the middle of that conversation ... I realized ... the thing that I had

incongruence trouble doing was looking at the slide and figuring out what it was about just by looking at it.” (G18)

"I was sort of getting caught up ... I wish I had checked in a little bit more earlier in the week. But I was a little swamped.” (G10*)

“[The givers should have] recognize[ed] that everything isn’t fully baked in here [and I should have] tried to set that expectation up front ... I think we had a different expectation of how many times this thing was going to be disassembled and used and maintained.” (R03)

$\mathrm{G}$ = help-giver; $\mathrm{R}$ = help-receiver. The number following the letter indicates a specific individual informant. Informants marked with '*’ participated in Phase 2 of data collection (project team daily diaries and weekly interviews).

\section{Table 7: Examples of Helping Actions in Successful Helping Episodes}

\begin{tabular}{|c|c|}
\hline Concept & Representative Quotations \\
\hline \multirow[t]{3}{*}{$\begin{array}{l}\text { Help perceived } \\
\text { as on-target }\end{array}$} & $\begin{array}{l}\text { "[The givers] are both are very bright and sensitive people. And they intuitively, without having to try very } \\
\text { hard, know what's going to be the thing that's useful for a team at that stage. We didn't even actually } \\
\text { necessarily have to tell them, 'Oh, we're two weeks from the end, so blah, blah, blah.' They get it ... It's } \\
\text { useful to establish some guardrails around the sort of input that you want ... And they were just very good. } \\
\text { Obviously we steered them there, but they also didn't deviate.” (R12) }\end{array}$ \\
\hline & $\begin{array}{l}\text { "He helped write the next phase proposal. And he’s really pushing as an engineer, which is awesome ... } \\
\text { [saying things like,] 'Here's what you guys need in the end. Here's how long it takes to produce.' ... which } \\
\text { is exactly what I needed: someone who’d think through all that stuff. And that's what he did.” (R17*) }\end{array}$ \\
\hline & $\begin{array}{l}\text { "[The giver] came in, and he basically dove in with us and started designing different types of screens with } \\
\text { us ... I asked him different questions here and there on the screens I was designing, ... things like, '[Do] } \\
\text { you think I should put that button here or that button there?' or higher-level questions, like, 'do we really } \\
\text { need that screen or is it kind of useless?’” (R19*) }\end{array}$ \\
\hline
\end{tabular}

Interaction "I was asking questions [such as], 'Could we do this?' and 'Could we do this?' And ... we thought about proceeds that, and [decided that] we can't, for this reason. And others sort of generated a conversation. [The receivers conversationally are] very sharp guys; they'd take my stupid question and twist it around to something that maybe made sense, and discuss that for a while.” (G11)

"[We used the] usual CDF process, Post-Its and Sharpies. [The givers said things like], 'I have a question here,' [or] 'That's not making sense to me,' or 'Could we say this thing this way?' [or] 'Is there a reason that this point is going in front of that point?'” (R12)

“I think they were thinking: 'There’s this tool, and there’s this piece, and there's all these parts that people can use on each of these two websites.' And I was like, 'OK, well, what's the primary purpose of the website? Why is it there?' And [a receiver] especially, who’s been involved with the project for much longer, articulated that, and I think it helped us.” (G10*)

$\mathrm{G}$ = help-giver; $\mathrm{R}$ = help-receiver. The number following the letter indicates a specific individual informant. Informants marked with '*' participated in Phase 2 of data collection (project team daily diaries and weekly interviews). 
Table 8: Examples of Assessing Helpfulness in Successful Helping Episodes

\begin{tabular}{ll}
\hline Concept & Representative Quotations \\
\hline $\begin{array}{l}\text { Instrumental } \\
\text { progress }\end{array}$ & "I think [the episode] added some clarity to what they were doing, because they get so kind of deep down \\
& about the tools and what they're going to build and all of that.” $\left(\mathrm{G} 10^{*}\right)$ \\
& "[The team said], 'Yeah, we have a plan now. Like, we don’t need to talk more. We can start to really figure \\
& out what this means ... I'd say [the framework developed during the helping episode] formed the backbone \\
& of what they delivered." (G08) \\
& "We got it all hammered out ... If [the receiver] had to do that herself ... it would have been on her \\
& vacation, and/or she wouldn’t have been able to think about anything else." (G07*) \\
& "For me, [the episode] was a really powerful interaction, because you get to a point where you've thought \\
& about this stuff and synthesized it and digested it certain ways, and it gets hard to push beyond that. And I \\
& come from a really small firm where I’m used to doing a lot of this stuff much more on my own, and just \\
& kind of bashing my head against the wall, on my own, until it sort of splits open and divulges something else \\
& ... And so that conversation was like skipping a stone. It was the first skip.” (R04)
\end{tabular}

Positive "I was like, this is kind of fun. I feel like we're getting somewhere.” (G08)

emotions or

reduced anxiety

"Those conversations are fairly energizing. And there is a little bit of-nervousness is overstating it, but there’s like, OK, fresh eyes.” (R12)

"It was terrifically helpful because it didn’t present a point of view that forced me to take a radical turn in another direction.” (R04)

$\mathrm{G}$ = help-giver; $\mathrm{R}$ = help-receiver. The number following the letter indicates a specific individual informant. Informants marked with '*’ participated in Phase 2 of data collection (project team daily diaries and weekly interviews).

\section{Table 9: Examples of Assessing Helpfulness in Unsuccessful Helping Episodes}

\begin{tabular}{ll}
\hline Concept & Representative Quotations \\
\hline Lack of progress & "The team didn’t successfully pick [the giver's suggestion] up and integrate it, and move it forward ... We \\
were on this baseline, people would push us up here, and then we'd end up down here again. And it was just \\
exhausting ... The whole thing felt very chaotic and unplanned.” (R04) \\
“It doesn’t seem to work to give him more than he’s asking for, because it’s not going to be useful in the \\
end ... I'll end up spending more time hunting for things that he’s just going to reject. So I felt less able to \\
help.” (G23) \\
“There wasn’t anything that was like so new and different ... I think we got better results from [an earlier] \\
brainstorm that we did with the more general group of designers.” (R13) \\
“[The episode] just wasn’t helpful ... It didn’t create any challenges or anything like that .... Rather than \\
something concrete coming out of it ... [it] turned out to be more confusing.” (R20*) \\
"It felt pretty inconclusive overall.” (G10*)
\end{tabular}

Negative "I gave up hope in a way ... it felt like rather than being a help, this network of input just sort of bogged us emotions down.” (R04)

"I felt like [the receiver] didn't want what I could offer ... I was feeling just like mowed down by her ambition and her desire to drive forward.” (G19)

"[The giver] just caused a lot of stress ... [The team] was frustrated.” (R18)

"[The episode] was harmful to my confidence ... I didn’t go home and cry myself to sleep. It was just annoying." (R12)

$\mathrm{G}$ = help-giver; $\mathrm{R}$ = help-receiver. The number following the letter indicates a specific individual informant. Informants marked with '*’ participated in Phase 2 of data collection (project team daily diaries and weekly interviews). 
Figure 1: A Process Model of Successful and Unsuccessful Helping Episodes

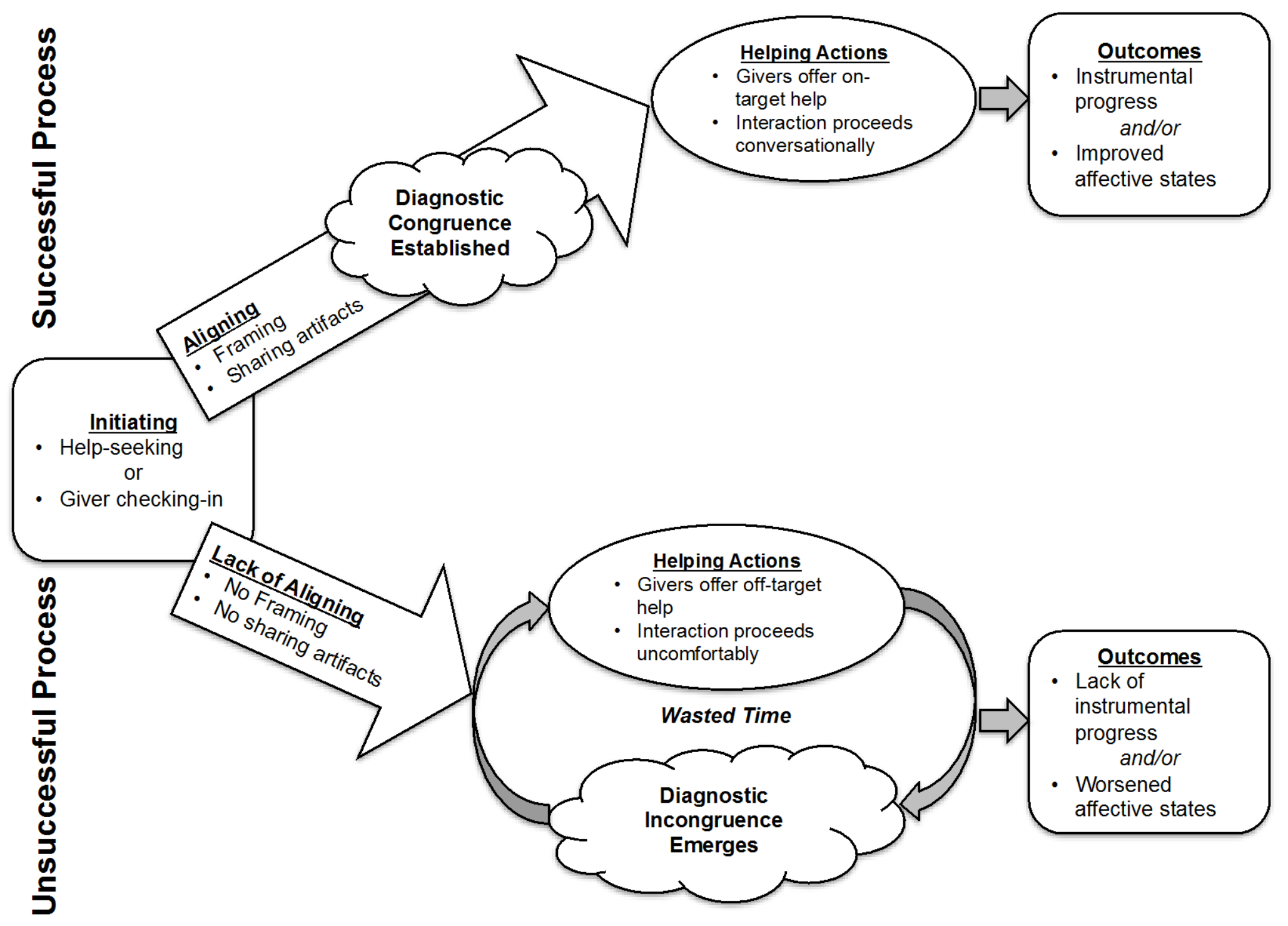

